\title{
Large-eddy simulation of mesoscale dynamics and entrainment around a pocket of open cells observed in VOCALS-REx RF06
}

\author{
A. H. Berner, C. S. Bretherton, and R. Wood \\ Department of Atmospheric Science, University of Washington, Seattle, Washington, USA \\ Received: 25 March 2011 - Published in Atmos. Chem. Phys. Discuss.: 2 May 2011 \\ Revised: 29 September 2011 - Accepted: 12 October 2011 - Published: 24 October 2011
}

\begin{abstract}
Large-eddy simulations of a pocket of open cells (POC) based on VOCALS Regional Experiment (REx) NSF C-130 Research Flight 06 are analyzed and compared with aircraft observations. A doubly-periodic domain $192 \mathrm{~km} \times 24 \mathrm{~km}$ with $125 \mathrm{~m}$ horizontal and $5 \mathrm{~m}$ vertical grid spacing near the capping inversion is used. The POC is realized in the model as a fixed $96 \mathrm{~km}$ wide region of reduced cloud droplet number concentration $\left(N_{\mathrm{c}}\right)$ based on observed values; initialization and forcing are otherwise uniform across the domain. The model reproduces aircraftobserved differences in boundary-layer structure and precipitation organization between a well-mixed overcast region and a decoupled POC with open-cell precipitating cumuli, although the simulated cloud cover is too large in the POC. A sensitivity study in which $N_{\mathrm{c}}$ is allowed to advect following the turbulent flow gives nearly identical results over the $16 \mathrm{~h}$ length of the simulation (which starts at night and goes into the next afternoon).

The simulated entrainment rate is nearly a factor of two smaller in the less turbulent POC than in the more turbulent overcast region. However, the inversion rises at a nearly uniform rate across the domain because powerful buoyancy restoring forces counteract horizontal inversion height gradients. A secondary circulation develops in the model that diverts subsiding free-tropospheric air away from the POC into the surrounding overcast region, counterbalancing the weaker entrainment in the POC with locally weaker subsidence.
\end{abstract}

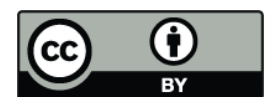

Correspondence to: A. Berner (andy.berner@gmail.com)

\section{Introduction}

Pockets of open cells (POCs; Bretherton et al., 2004; Stevens et al., 2005) embedded in regions of unbroken stratocumulus are symptomatic of aerosol-cloud-precipitation feedbacks in marine boundary layer (MBL) structure and cloud response, with stark differences in mesoscale organization, dynamics, and microphysics rapidly evolving locally between the POC and the surrounding overcast MBL. POCs may subsequently grow from an initial scale of a few hundred $\mathrm{km}^{2}$ to cover an area three orders of magnitude greater. One readily apparent result of the changes in boundary layer circulation is a significant reduction in cloud cover and area averaged liquid water path (LWP), and the resulting reduction in albedo over a broad area impacts planetary radiative balance and climate.

Several observational studies in the last decade have provided insight into POC processes. vanZanten and Stevens (2005) discussed observations from the second research flight of the DYCOMS II campaign and noted the presence of lower cloud droplet concentration and locally heavy precipitation organized in mesoscale cells within the POC, as well as a well mixed boundary layer in the closed cell regions in spite of significant cloud base precipitation. Sharon et al. (2005) documented sharp reductions in cloud droplet number and aerosol concentrations across the boundary of a NE Pacific "rift" (elongated POC). Similar features were found in southeastern Pacific (SEP) stratocumulus. Comstock et al. (2005) used observations from the EPIC $2001 \mathrm{Sc}$ campaign to investigate mesoscale variability in the Southeast Pacific (SEP) stratocumulus regime, noting that heavy drizzle in POCs stimulated enhanced horizontal variability in the surface due to cold pools. Kollias et al. (2004) showed

Published by Copernicus Publications on behalf of the European Geosciences Union. 
a striking depletion of accumulation-mode aerosols on a later cruise as a POC passed overhead.

In 2008, the VAMOS Ocean Cloud Atmosphere Land Study (VOCALS) Regional Experiment (REx) sampled several POCs in the SEP stratocumulus regime (Wood et al., 2011a). Research Flight 06 (RF06) sampled across the boundary of an archetypical mature POC on the morning of 28 October 2008 in the vicinity of $18^{\circ} \mathrm{S} 80^{\circ} \mathrm{W}$. Wood et al. (2011b) analyzed the RF06 observations. Their summary of the dynamic and microphysical conditions in the MBL provide the information needed to initialize the simulations described in this paper and a means to gauge the fidelity of the model's behavior.

LES modeling of the mesoscale structure of POCs has only recently become feasible, as reasonable simulation requires a domain large enough to support mesoscale variability. Savic-Jovcic and Stevens (2008) examined the role of drizzle in the transition of closed to open cellular structure with $50 \mathrm{~m}$ horizontal grid spacing on a $25.6 \mathrm{~km}$ by $25.6 \mathrm{~km}$ domain, finding that subcloud evaporation of precipitation and surface cold pooling are critical to the development of mesoscale organization and the transition to a more open cellular pattern. Wang and Feingold (2009a) extended this work to yet larger domains of $60 \mathrm{~km}$ by $60 \mathrm{~km}$, confirmed the sensitivity of cloud structure to precipitation, and phrased the sensitivity to open cellular precipitation in terms of the aerosol concentration. Wang and Feingold (2009b) examined the mesoscale cellular structure and dynamics resulting from a cloud condensation nuclei $(\mathrm{CCN})$ gradient across the domain. Wang et al. (2010) examined the efficacy of moisture, temperature, and $\mathrm{CCN}$ perturbations in changing the boundary layer structure, and suggested the importance of cold pooling as a mechanism for altering boundary layer structure at a distance from the perturbation. Most recently Kazil et al. (2011) examined closed to open cellular transition for the VOCALS RF06 case using the WRF-CHEM model, allowing the successful replication of an ultra-clean layer within modeled open cells.

In this study, we investigate the dynamics that arise at the boundary of the POC and examine the sensitivity of the dynamics to two simplified treatments for the $N_{\mathrm{c}}$ distribution, primarily examining the case in which $N_{\mathrm{c}}$ is held fixed in the POC and overcast at different, observationally representative values. While this framework cannot address the detailed complexities of cloud-aerosol interactions, the dynamics arising from a simple microphysical gradient are a reasonable starting point for analyzing the mesoscale dynamics arising within the POC/overcast system. Through comparison to the observations available from RF06 as described in Wood et al. (2011b), we extensively examine the fidelity of LES in representing the POC. Finally, we look at entrainment differences and POC-scale circulations between the overcast and open cellular regions.

\section{Model formulation}

The simulations in this paper were performed using version 6.7 of the System for Atmospheric Modeling (SAM). A detailed description of SAM may be found in Khairoutdinov and Randall (2003). SAM uses an anelastic dynamical core with liquid-ice static energy $\left(s_{\mathrm{li}}=c_{\mathrm{p}} T+g z-L q_{1}-L_{\mathrm{f}} q_{\mathrm{i}}\right)$ as the moist-conserved temperature-like variable, where $c_{\mathrm{p}} T$ is thermal energy, $g z$ is geopotential energy, $L q_{1}$ is latent energy in the liquid phase, and $L_{\mathrm{f}} q_{\mathrm{i}}$ is latent energy in the ice phase.

Moisture variables are computed with the two-moment Morrison microphysics scheme (Morrison et al., 2008). Total water mass mixing ratio $\left(q_{\mathrm{t}}\right)$ is prognosed, from which water vapor mixing ratio $\left(q_{\mathrm{v}}\right)$ and cloud water mixing ratio $\left(q_{\mathrm{c}}\right)$ are diagnosed by saturation adjustment, with additional prognostic equations for rain mass mixing ratio $\left(q_{\mathrm{r}}\right)$ and number concentration $\left(N_{\mathrm{r}}\right)$. No ice phase calculations are needed for the warm rain case of subtropical stratocumulus convection. In lieu of an interactive bulk aerosol module, for this study the microphysics code is modified to treat cloud droplet number concentration $\left(N_{\mathrm{c}}\right)$ as either a fixed quantity or as an advected scalar without microphysical tendencies.

The inclusion of cloud droplet sedimentation within the microphysical parameterization is important for the correct modeling of cloud-top entrainment (Ackerman et al., 2004, 2009; Bretherton et al., 2007). The Morrison scheme represents cloud droplet sedimentation using an assumed gamma distribution of droplet sizes. For comparison with observations, the millimeter wave radar simulator QUICKBEAM (Haynes et al., 2007) is coupled into our simulation and makes use of the microphysical fields.

The CAM3 radiation package (Collins et al., 2006) is called every $15 \mathrm{~s}$, with solar zenith angle computed for the study region location, $17.5^{\circ} \mathrm{S} 79.5^{\circ} \mathrm{W}$, and with effective radius computed from $q_{\mathrm{c}}$ and $N_{\mathrm{c}}$.

The simulations in this study use the TKE closure of Deardorff (1980) for the sub-grid scheme. Surface fluxes are computed in each column based on Monin-Obukhov similarity theory. Coriolis force is included based on the specified latitude with the model run in an $f$-plane configuration.

The vertical grid spacing is $30 \mathrm{~m}$ near the surface, shrinking to $5 \mathrm{~m}$ between $1300-1650 \mathrm{~m}$ to encompass the inversion layer, then gradually stretching to a domain top set at $30 \mathrm{~km}$ for convenient computation of radiative fluxes, for a total of 192 vertical levels. The vertical grid structure is depicted in Fig. 1.

To simulate the large horizontal extent of a POC, we choose a horizontal domain size of $24 \mathrm{~km}$ by $192 \mathrm{~km}$, with the longer dimension oriented perpendicular to the POC edge and the mean wind in the boundary layer essentially parallel to the POC axis. Doubly periodic horizontal boundary conditions are applied. For stability reasons, the grid is advected with a specified boundary layer wind. For computational efficiency, horizontal grid spacing is a relatively coarse $125 \mathrm{~m}$. 


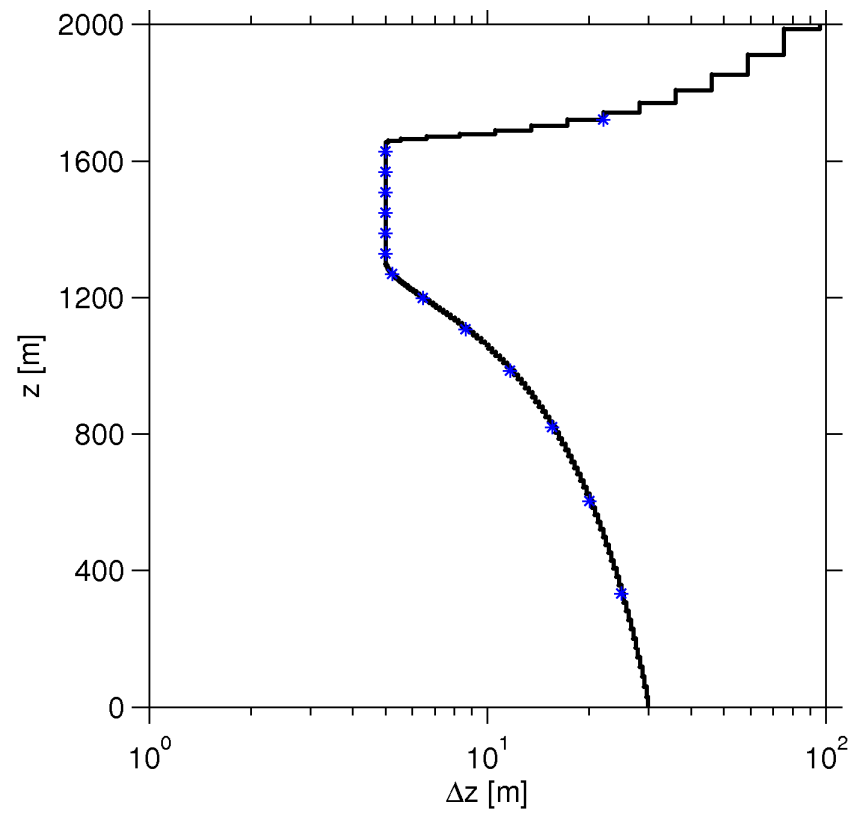

Fig. 1. Vertical model grid plotted as $\Delta z$ vs. $z$. Blue asterisks are plotted every 12 model levels.

Our choice of horizontal and vertical grid spacing was guided by sensitivity tests in a smaller domain using horizontally homogeneous initial conditions. By selecting a grid that produced surface fluxes and LWP values similar to the observations, it was hoped that errors from spurious numerical diffusion leading to over-entrainment would be reduced. For a more detailed discussion of the grid sensitivities of LES modeling studies, the interested reader is referred to Bretherton et al. (1998) and Stevens et al. (1999). Table 1 shows values for the surface fluxes and liquid water path averaged over six hours after spin-up for these simulations. Past experience suggested that a $5 \mathrm{~m}$ grid spacing through the inversion layer is necessary when using SAM to minimize spurious numerical enhancement of stratocumulus entrainment. If the surface latent and sensible fluxes are fixed to match observations ("FF" cases), the simulations are insensitive to the near-surface vertical grid spacing but they are still somewhat sensitive to horizontal grid spacing. We selected the $125 \mathrm{~m}$ grid for computational efficiency; it produced slightly larger LWP than the $50 \mathrm{~m}$ grid (see top two rows of the table) due to a lower entrainment rate.

We found that with $125 \mathrm{~m}$ horizontal grid spacing and interactive Monin-Obukhov surface fluxes ("MO" rows in the table), the surface flux was sensitive to near-surface vertical grid spacing. In particular, rows 3-4 of the table show that use of a $5 \mathrm{~m}$ vertical grid spacing near the surface unrealistically inhibits surface fluxes, while a $30 \mathrm{~m}$ grid spacing gives realistic results, so the latter was selected. After our simulations were completed, observational estimates of LWP in the overcast region were reduced from $240 \mathrm{~g} \mathrm{~m}^{-2}$ (comparable to our simulations) to $170 \mathrm{~g} \mathrm{~m}^{-2}$.
Table 1. Selection of runs used during sensitivity studies. FF runs use specified surface fluxes and identical vertical spacing to investigate sensitivity of LWP to horizontal grid spacing. MO runs calculate fluxes using Monin-Obukhov similarity theory and investigate the effects of first grid cell aspect ratio on the calculated fluxes.

\begin{tabular}{lccc}
\hline Run & Aspect Ratio & $\begin{array}{c}\text { Latent/Sensible Flux } \\
\mathrm{W} \mathrm{m}^{-2}\end{array}$ & $\begin{array}{c}\text { LWP } \\
\mathrm{g} \mathrm{m}^{-2}\end{array}$ \\
\hline FF 125dx 5dz & 25 & $148 / 3$ & 211 \\
FF 50dx 5dz & 10 & $148 / 3$ & 168 \\
MO 125dx 30dz & 4.16 & $147 / 7$ & 216 \\
MO 125dx 5dz & 25 & $73 / 4$ & 176 \\
\hline
\end{tabular}

\section{Initialization and forcing}

\subsection{Temperature, moisture, and wind}

The domain is initialized uniformly in all columns with the thermodynamic and wind profiles depicted in Fig. 2. Below $3 \mathrm{~km}$, the thermodynamic profiles are based on C-130 profiles outside the POC; above this level the NCEP FNL (National Center for Environmental Prediction Final) operational analysis from 28 October at 06:00 UTC interpolated to the sampling location is used. A steady geostrophic wind profile is used to force model winds. Above $3 \mathrm{~km}$, we use the NCEP FNL wind profile. Below $3 \mathrm{~km}$, we have adjusted the geostrophic wind profile based on pilot runs until the mean wind profile after spin-up resembles observations.

Our runs are initialized at 22:00 Local Solar Time (LST), because pilot simulations showed that it takes at least six hours for the mesoscale cell dynamics to fully spin up. As the initial sounding is taken from RF06, and the simulated boundary layer deepens slightly with time, the simulated boundary layer is about $100 \mathrm{~m}$ deeper than observed at the corresponding local time.

\subsection{Subsidence}

The VOCALS study region is subject to a strong diurnal cycle of subsidence (Bretherton et al., 2004; Garreaud and Munoz, 2004; Wood et al., 2009). Subsidence is difficult to establish from available observations. For simplicity, we assumed a constant divergence of $1.33 \times 10^{-6} \mathrm{~s}^{-1}$ between the surface and $3000 \mathrm{~m}$. This divergence is based on the daily average estimated subsidence rate of $w_{\mathrm{ls}}=-2 \mathrm{~mm} \mathrm{~s}^{-1}$ at $1500 \mathrm{~m}$ based on NCEP analysis (Wood et al., 2011b), and is consistent with that paper's alternative estimates based on ECMWF analysis and QuikScat wind divergence. While including the mean subsidence diurnal cycle could well be important in modulating cycles of LWP, precipitation, and cloud fraction within the POC, the current study is more focused on dynamical interactions with the surrounding overcast during the eight hour RF06 sampling period, for which subsidence diurnal cycles are probably less important. Furthermore, 

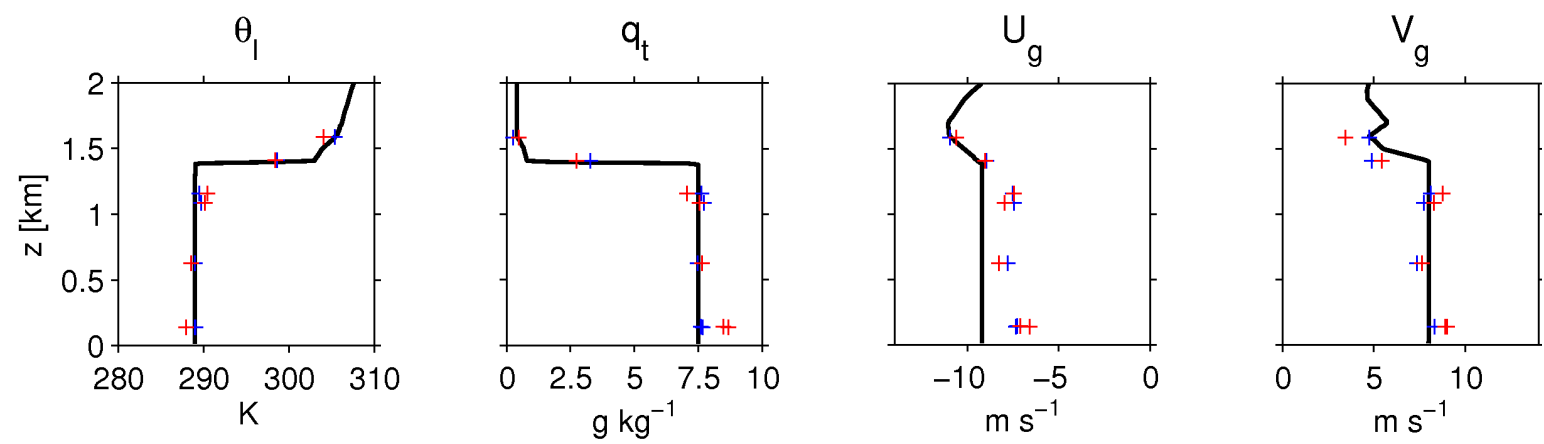

Fig. 2. Profiles used to initialize the LES. The geostrophic wind profiles are used as steady forcings as well as initial conditions. Only heights less than $2 \mathrm{~km}$ are shown. Observations from RF06 are overlaid, blue from within the OVC, red from within the POC.

Caldwell and Bretherton (2009), which included diurnal variations of subsidence in an LES study of the diurnal cycle of stratocumulus in the Southeast Pacific, suggests that while clearly modulating inversion height, the subsidence diurnal cycle projects less strongly on cycles of liquid water path and cloud fraction. An examination of sensitivity to the subsidence cycle is left for future work.

\subsection{Microphysics}

The cloud droplet concentration $N_{\mathrm{c}}$ is initialized across the domain as a function of the $x$ coordinate with $44 \mathrm{~km}$ of $N_{\mathrm{c}}=60 \mathrm{~cm}^{-3}$, representing the overcast region, followed by an $8 \mathrm{~km}$ half-cosine transition to $88 \mathrm{~km}$ of $N_{\mathrm{c}}=10 \mathrm{~cm}^{-3}$, representing the POC, followed by a symmetric $8 \mathrm{~km}$ transition back to $44 \mathrm{~km}$ of $N_{\mathrm{c}}=60 \mathrm{~cm}^{-3}$.

A simulation with fixed $N_{\mathrm{c}}$ (NCFIXED) is initialized with vertically uniform $N_{\mathrm{c}}$, whereas a simulation in which $N_{\mathrm{c}}$ freely advects and turbulently mixes without sources and sinks (NCADVECT) has a horizontally uniform layer of $N_{\mathrm{c}}=50 \mathrm{~cm}^{-3}$ above the inversion to the domain top. Within the context of our simulations, we make the idealization that all available nuclei are activated at saturation, so that advected $N_{\mathrm{c}}$ in unsaturated portions of the domain is identical to the number of CCN. The Morrison microphysics scheme includes an option to prognostically predict $N_{\mathrm{c}}$ from two fixed, lognormal aerosol modes. In small-domain pilot runs using this option, a single accumulation mode was specified with uniform aerosol concentrations of 5,10 , or $30 \mathrm{~cm}^{-3}$. In each run, almost all the aerosol activated in all the clouds, giving results nearly identical to fixing $N_{\mathrm{c}}$ directly. We infer that a realistic treatment of aerosol scavenging (e.g. Kazil et al., 2011) is required to simulate the large differences between droplet concentration observed in the RF06 POC between the cumulus updrafts and the thin stratiform clouds. One can regard NCADVECT as a crude test of the sensitivity of the results to a long adjustment timescale for aerosolcloud-microphysics interaction to establish an equilibrium droplet concentration.
The initial distributions for both configurations are depicted in Fig. 3. These values were selected as an idealization of observations during the research flight, where $N_{\mathrm{c}}$ in the overcast region varied from $100 \mathrm{~cm}^{-3}$ far from the POC boundary to $40 \mathrm{~cm}^{-3}$ in the vicinity of the transition, and $P O C$ values ranged from less than $1 \mathrm{~cm}^{-3}$ in thin stratocumulus near the inversion up to $30 \mathrm{~cm}^{-3}$ in cumulus updrafts. Profiles above the POC indicated a free tropospheric accumulation-mode aerosol concentration of roughly $50 \mathrm{~cm}^{-3}$ (Wood et al., 2011b).

The change in $N_{\mathrm{c}}$ creates a sharp gradient in precipitation between the overcast and POC regions as the model spins up, as lower POC $N_{\mathrm{c}}$ and initially homogeneous total water $\left(q_{t}\right)$ result in larger mean droplet radii and enhanced autoconversion. All differences in the simulations between the overcast and POC regions of the domain ultimately derive from the $N_{\mathrm{c}}$ initialization alone, since all other aspects of the forcing and initialization are horizontally homogeneous.

\section{Results and discussion}

We begin with a brief overview of the model evolution. Figure 4 shows a sequence of domain snapshots every two hours from the NCFIXED run, using a pseudo-albedo derived from the cloud optical depth, as described in Zhang et al. (2005). The lower albedo evident within the POC is partially a Twomey effect due to a $50 \%$ larger effective radius due to the smaller $N_{\mathrm{c}}$, but even more important is a rapid halving of LWP compared to the overcast region.

Within a few hours, the droplet concentration differences lead to two distinctly different regimes interacting across a boundary, results qualitatively similar to Wang and Feingold (2009b). Cloud morphology in the high $N_{\mathrm{c}}$ areas of the domain is closed cellular, while in the low $N_{\mathrm{c}}$ region, it is a bit more ambiguous, with optically thin cloud punctuated by bright cumuliform updrafts and some cloud free regions. As the simulation progresses, the characteristic cell size in both regions grows, with the scale growing more rapidly in the more cumuliform POC than in the overcast closed cellular regions to either side. 
Initial $\mathrm{N}_{\mathrm{c}}$ distribution (fixed case)

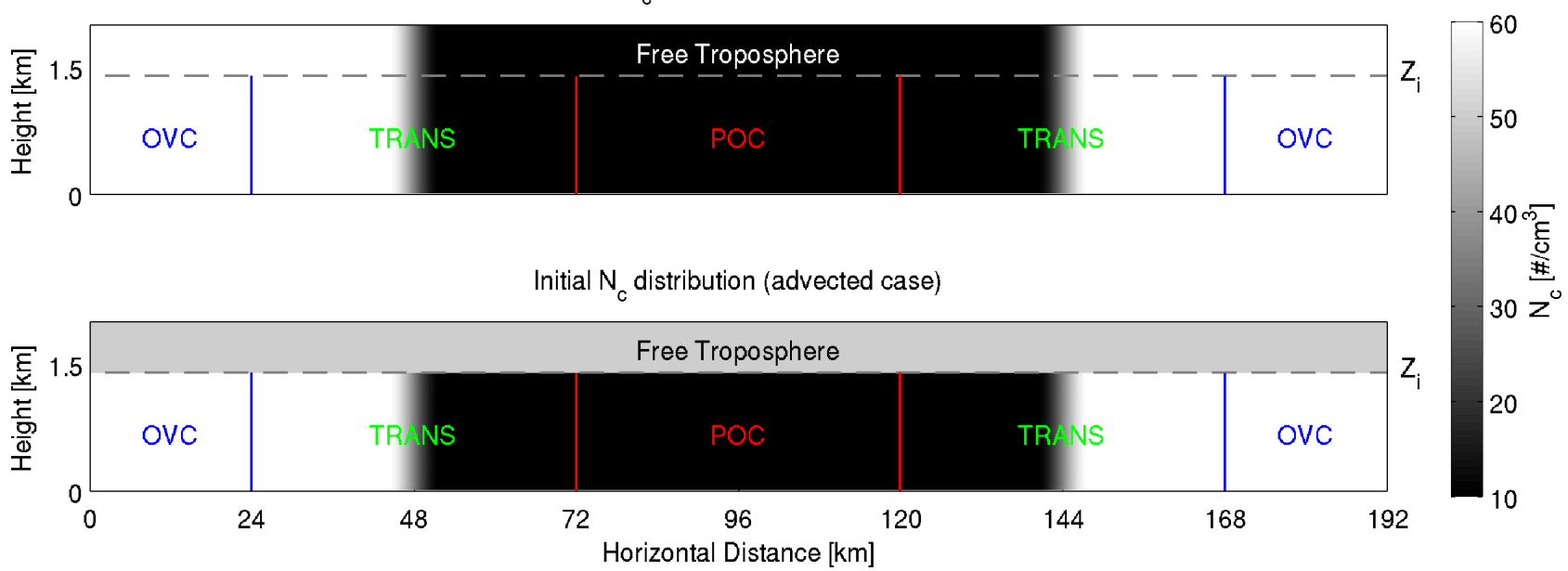

Fig. 3. $x-z$ cross-section of $N_{\mathrm{c}}$ initialization for the NCFIXED and NCADVECT simulations. Sampling regions for profiles, time-series, and other statistics are also depicted. Initialization is homogeneous in $y$. Red lines enclose the POC sampling region, the blue lines to domain edge enclose the OVC sampling region, and all remaining area is considered transitional (TRANS).
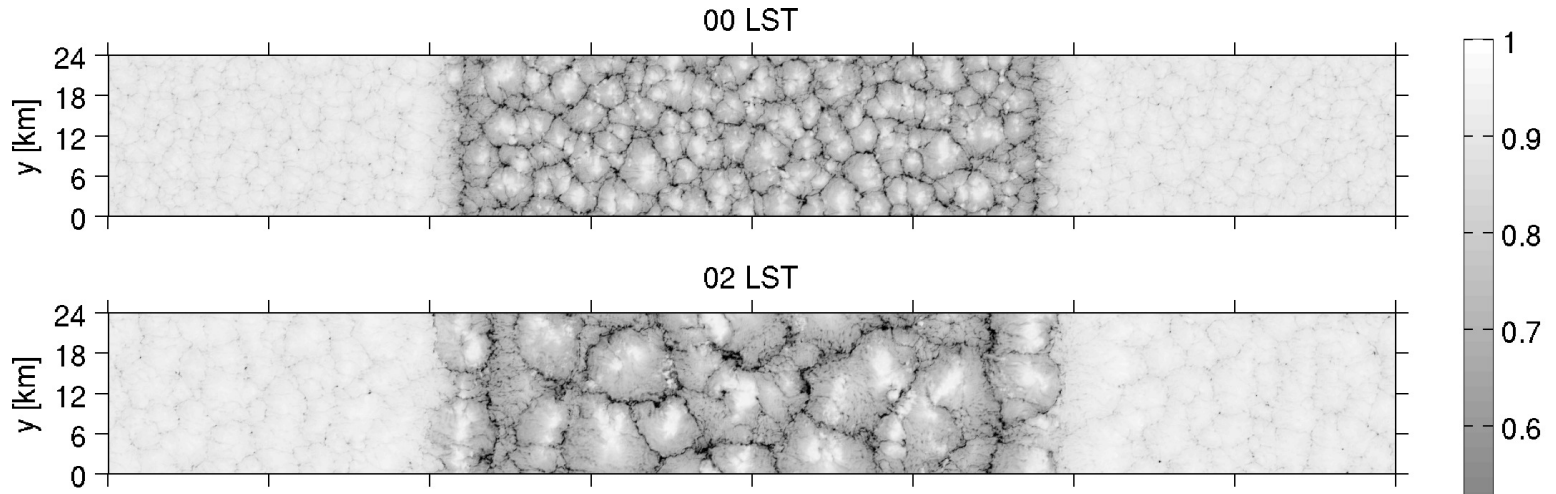

04 LST
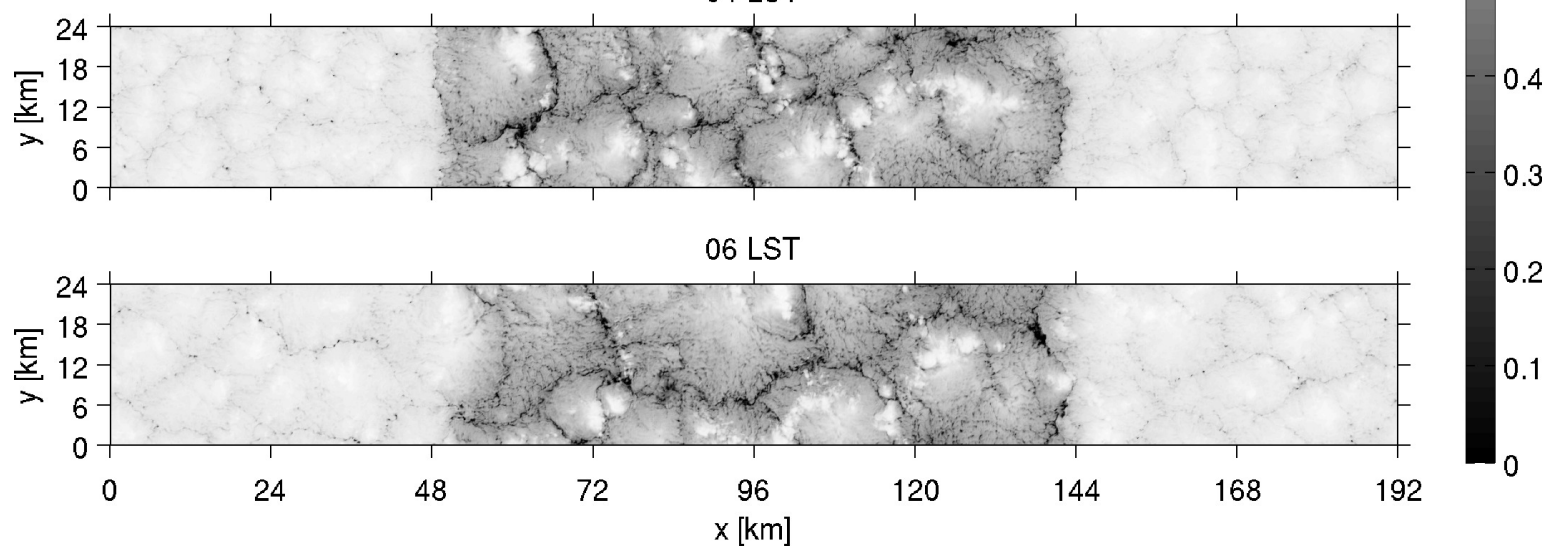

Fig. 4. Domain snapshots of pseudo-albedo for the NCFIXED run, computed from cloud optical depth following Zhang et al. (2005). Note that 00:00 LST is two hours into the simulation. 


\subsection{Sensitivity to $\mathrm{CCN}$ advection}

As discussed in Sect. 3.3, a sensitivity study NCADVECT was run, treating $N_{\mathrm{c}}$ as an advected tracer without sources or sinks, crudely representing the impact of a long timescale for cloud condensation nucleus concentration to respond to microphysically-driven differences in sinks and sources inside vs. outside the POC.

Figure 5 shows $y$-averaged vertical cross-sections of $N_{\mathrm{c}}$ during NCADVECT. Mesoscale circulations begin to diffuse the distribution of $N_{\mathrm{c}}$, blurring and widening the transition. Entrainment from above also dilutes the gradient. Over the course of the first eight hours, the gradients on either side of the POC widen to nearly $24 \mathrm{~km}$. The $0.01 \mathrm{~g} \mathrm{~kg}^{-1}$ contour of $y$-averaged cloud water $q_{\mathrm{c}}$ demonstrates that this correspondingly broadens the initially abrupt transition in cloud thickness, as well. However, after $8 \mathrm{~h}$, the POC-scale gradients in $N_{\mathrm{c}}$ are still largely intact. After $16 \mathrm{~h}$, the $N_{\mathrm{c}}$ has horizontally diffused to a much greater extent (not shown). For the POC to persist over a period of days, active microphysical maintenance of the cloud condensation nucleus gradient at its edges is needed to prevent PBL circulations from mixing it out.

Figure 6 shows that the LWP is remarkably similar between the NCFIXED and NCADVECT cases over the entire period of simulation. While the diffused gradient in LWP evident at the POC edges in the NCADVECT run by 04:00 LST is likely a result of the variation in $N_{\mathrm{c}}$ treatment, remaining variations are not readily attributed to a structural difference between the runs. The high degree of correlation between simulations is corroborated by the time series of Fig. 7, as differences between statistics of the fixed and advected cases are nearly indistinguishable over the nocturnal portion of the runs. Henceforth, we will just show results from the NCFIXED simulation.

\subsection{Validation}

For sampling purposes and further analysis, the overall domain is decomposed into three sampling regions depicted in Fig. 3: overcast (hereafter OVC), POC, and transition (hereafter TRANS). Figure 7 shows time series for key parameters for the different sampling regions over the course of model integration for all runs and sensitivity studies. Comparisons of major parameters with observations are made for the period from 02:00-04:00 LST in the NCFIXED run, during which time the liquid water path (LWP) has essentially equilibrated (Fig. 7c) and there is little or no surface precipitation in the overcast region (Fig. 7d). A selection of these comparisons are summarized in Table 2.

Time series of latent and sensible heat fluxes (LHF/SHF) are shown in Fig. 7a and b. The LHF and SHF from Wood et al. (2011b) estimated from aircraft observations using bulk formulae are $160 \mathrm{~W} \mathrm{~m}^{-2}$ for LHF and $9 \mathrm{~W} \mathrm{~m}^{-2}$ for SHF in the OVC region, with POC-region estimates of $122 \mathrm{~W} \mathrm{~m}^{-2}$ for LHF and $15 \mathrm{~W} \mathrm{~m}^{-2}$ for SHF. Model-mean values during the comparison period, $148 \mathrm{~W} \mathrm{~m}^{-2} \mathrm{LHF}$ and $8 \mathrm{~W} \mathrm{~m}^{-2} \mathrm{SHF}$
Table 2. Comparison of a variety of observed OVC and POC mean values with LES output sampled from the respective model regions during the two-hour period (model time 02:00-04:00 LST) used for LES validation.

\begin{tabular}{lcc}
\hline Measurement & $\begin{array}{c}\text { Observed } \\
\text { (OVC/POC) }\end{array}$ & $\begin{array}{c}\text { LES } \\
(\text { OVC/POC })\end{array}$ \\
\hline LHF $\left(\mathrm{W} \mathrm{m}^{-2}\right)$ & $160 / 122$ & $148 / 122$ \\
SHF $\left(\mathrm{W} \mathrm{m}^{-2}\right)$ & $9 / 15$ & $8 / 17$ \\
LWP $\left(\mathrm{g} \mathrm{m}^{-2}\right)$ & $170 / 141$ & $249 / 118$ \\
Cloud Fraction $(\%)$ & $100 / 60$ & $100 / 99$ \\
Surface Precip $\left(\mathrm{mm} \mathrm{day}^{-1}\right)$ & $0.1 / 1.85$ & $0.01 / 1.5$ \\
\hline
\end{tabular}

in the OVC and $122 \mathrm{~W} \mathrm{~m}^{-2} \mathrm{LHF}$ and $17 \mathrm{~W} \mathrm{~m}^{-2} \mathrm{SHF}$ in the POC, are in good agreement with the observations. However, LHF slowly drops in both regions throughout the run, which can be attributed to a gradual moistening of the lowest layer due to undercutting cold pools spreading from the POC and the development of surface precipitation beneath the OVC region.

The LWP time series in Fig. 7c shows that the OVC region has more than double the LWP of the POC from after spin-up to an hour after model sunrise at 06:00 LST. In spite of this, the highest grid-column LWP values are found within the POC in intense drizzle cells under the cumuliform cell walls. For the comparison period, model LWP in the OVC is $249 \mathrm{~g} \mathrm{~m}^{-2}$ and $118 \mathrm{~g} \mathrm{~m}^{-2}$ in the POC as an area average. Wood et al. (2011b) reports cloud-conditional LWP as $170 \mathrm{~g} \mathrm{~m}^{-2}$ in the OVC region and $235 \mathrm{~g} \mathrm{~m}^{-2}$ in the POC; multiplying the latter by the reported $60 \%$ cloud cover in the POC gives an areal average of $141 \mathrm{~g} \mathrm{~m}^{-2}$. This suggests that the model is exaggerating the difference in LWP in an areal-average sense, and yet there is too much thin stratus cloud remaining in the model POC.

Surface precipitation rate, plotted in Fig. 7 d, shows that the POC develops significant surface precipitation immediately during model spin up, whereas the OVC region only begins to develop surface precip during the 02:00-04:00 LST period, with average rates of $0.01 \mathrm{~mm} \mathrm{day}^{-1}$ in the OVC and $1.5 \mathrm{~mm} \mathrm{day}^{-1}$ in the POC. This is in good agreement with the average precipitation rates derived from the $2 \mathrm{D}-\mathrm{C}$ probe during near-surface aircraft legs, which were $0.1 \mathrm{~mm} \mathrm{day}^{-1}$ in the OVC region and $1.85 \mathrm{~mm} \mathrm{day}^{-1}$ in the POC.

The time series for cloud-fraction in Fig. 7e shows a relatively minor difference between the regions, with $100 \%$ coverage in the OVC and $99 \%$ coverage in the POC. Cloud fraction is defined using $\tau>0.3$, where $\tau$ is computed following Zhang et al. (2005). This stands in contrast to the significant observed difference in cloudiness, with near $100 \%$ coverage in the OVC and 55-60\% coverage in the POC. One possible reason is that the observed stratocumulus cloud has extremely low droplet concentrations (much less than $10 \mathrm{~cm}^{-3}$ ) away from the cumuliform clouds, which drizzle away their 

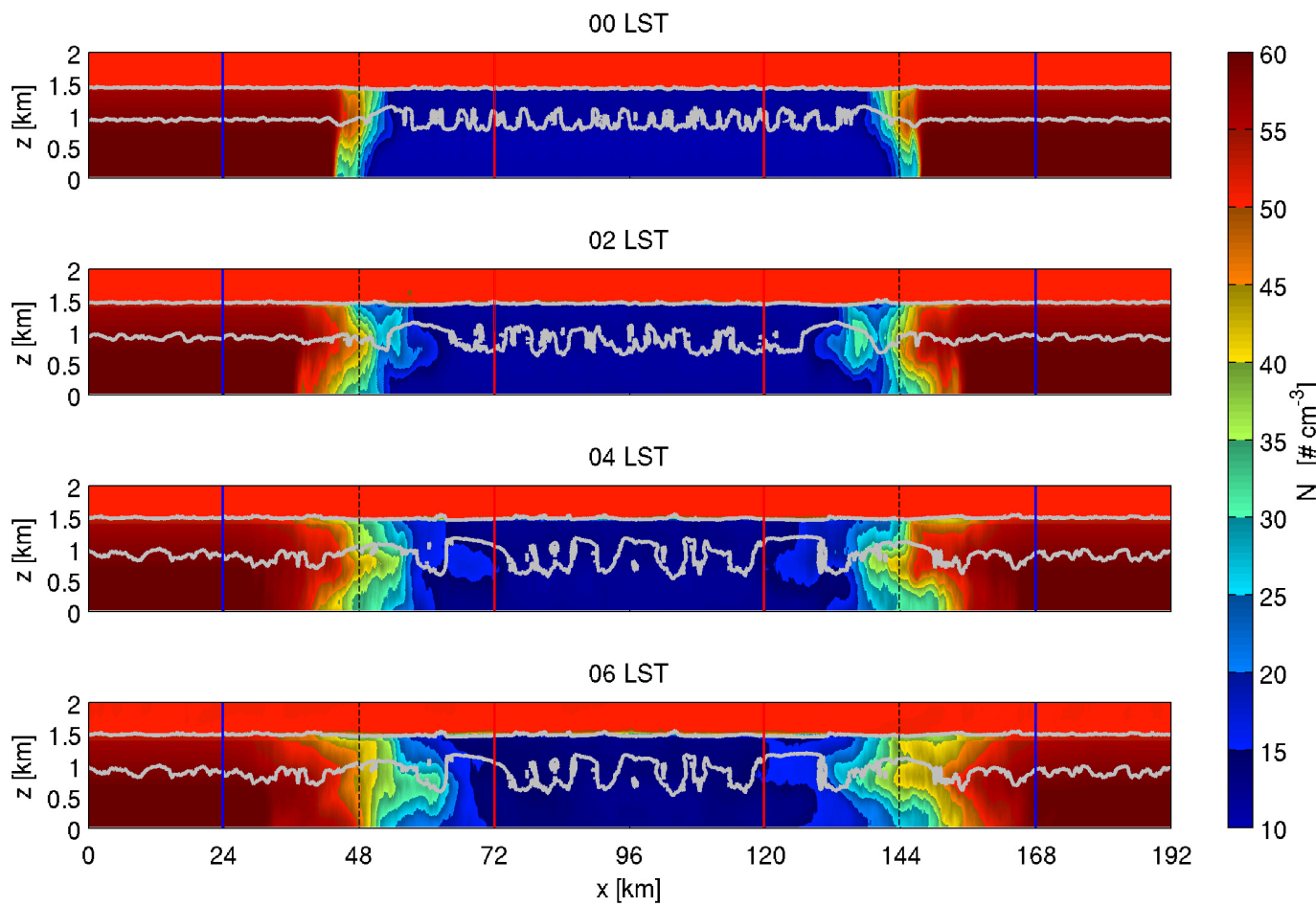

Fig. 5. Snapshots of $y$-averaged cross-sections of $N_{\mathrm{c}}$ from the NCADVECT run with the $0.01 \mathrm{~g} \mathrm{~kg}^{-1}$ contour of $y$-averaged $q_{\mathrm{c}}$, demonstrating the diffusion of the microphysical gradient by boundary layer turbulence and resulting cloud structure.

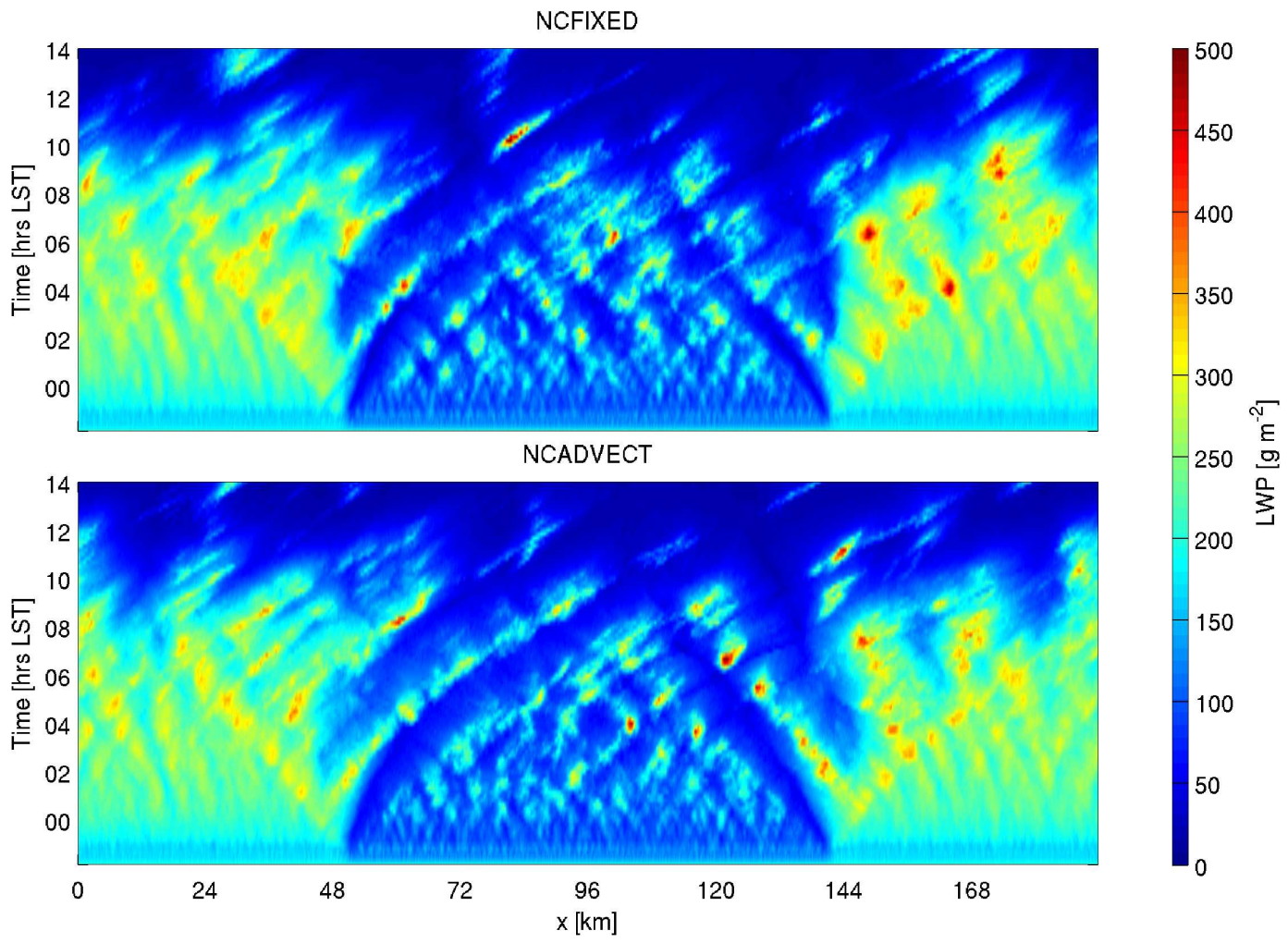

Fig. 6. Comparison of Hovmöller plots for $y$-averaged LWP from the NCFIXED and NCADVECT cases. 

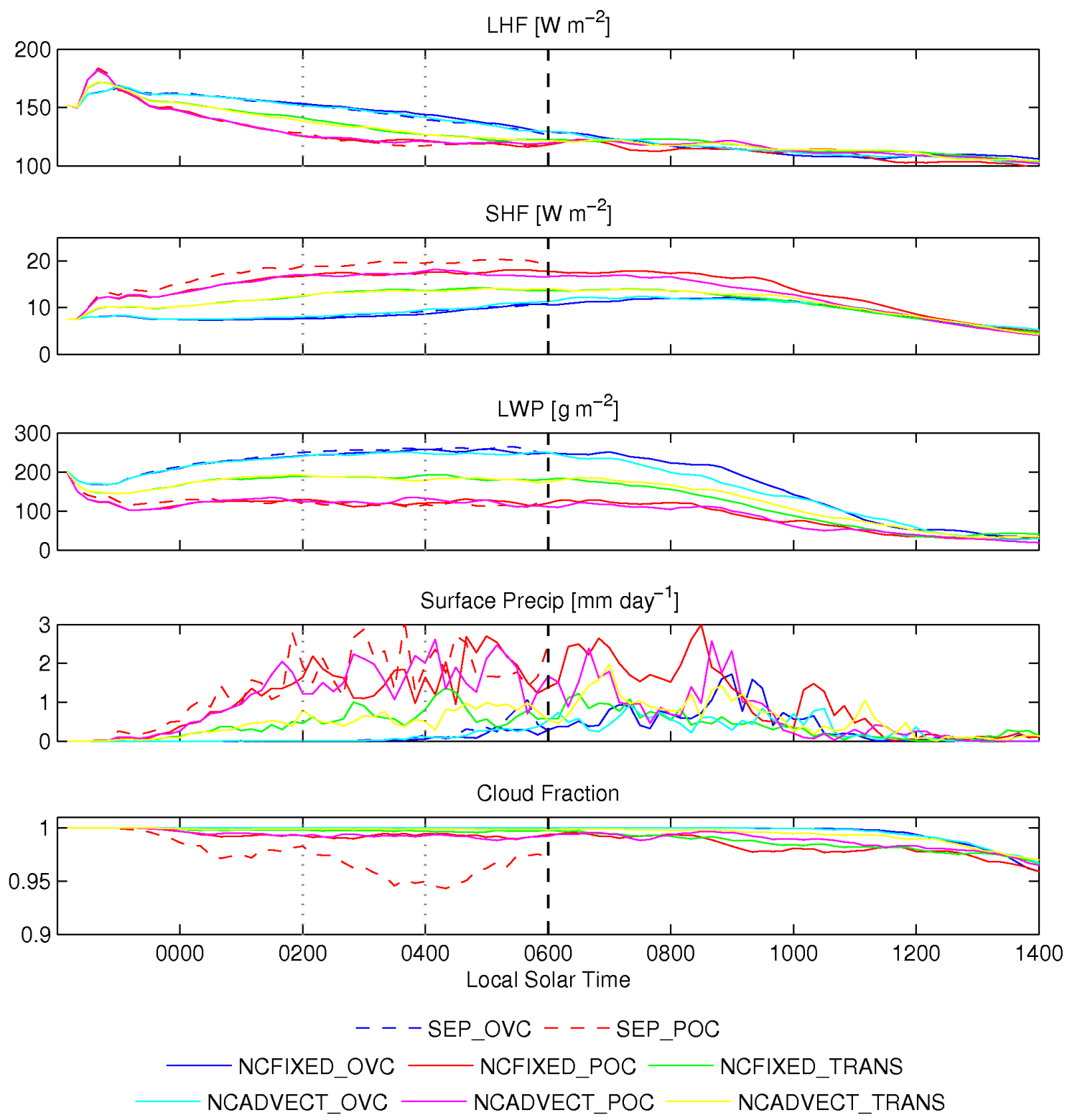

Fig. 7. Region averaged time series of key quantities for all model runs. Sunrise is at 06:00 LST (vertical dashed line).

liquid water despite being very thin; the fixed $N_{\mathrm{c}}$ across the POC does not allow for this behavior in the simulation. The inclusion of prognostic aerosol that interacts with LESsimulated cloud microphysics could potentially correct this discrepancy. A sensitivity study in a smaller domain shows that using a homogeneous $N_{\mathrm{c}}$ of $5 \mathrm{~cm}^{-3}$ results in cloud fraction in better agreement with observations; a full description of the sensitivity test appears below in Sect. 4.4.

After sunrise, the simulation alters considerably. LWP declines sharply, but while cloud fraction drops more sharply in the POC than it does in the overcast region, it does not fall below $90 \%$ in either region up to the end of the simulation at 14:00 LST. LWP, surface fluxes, surface precipitation, and cloud cover all begin to converge between the two regions by the end of the simulation, suggesting that the combination of a reduction in radiative forcing of the overcast boundary layer after sunrise and the spreading of the surface cold pool act to reduce moist and thermodynamic differences between the regions during the day. It is interesting that this convergence occurs in both the NCFIXED and NCADVECT runs, indicating that it is independent of the gradual mix-out of the $N_{\mathrm{c}}$ gradient that occurs in NCADVECT. The high bias in cloud fraction within the POC is likely important, and the limited domain size could play a role, but further study of this issue is required. As RF06 sampling strategy did not lend itself to capturing the temporal evolution of the POC 

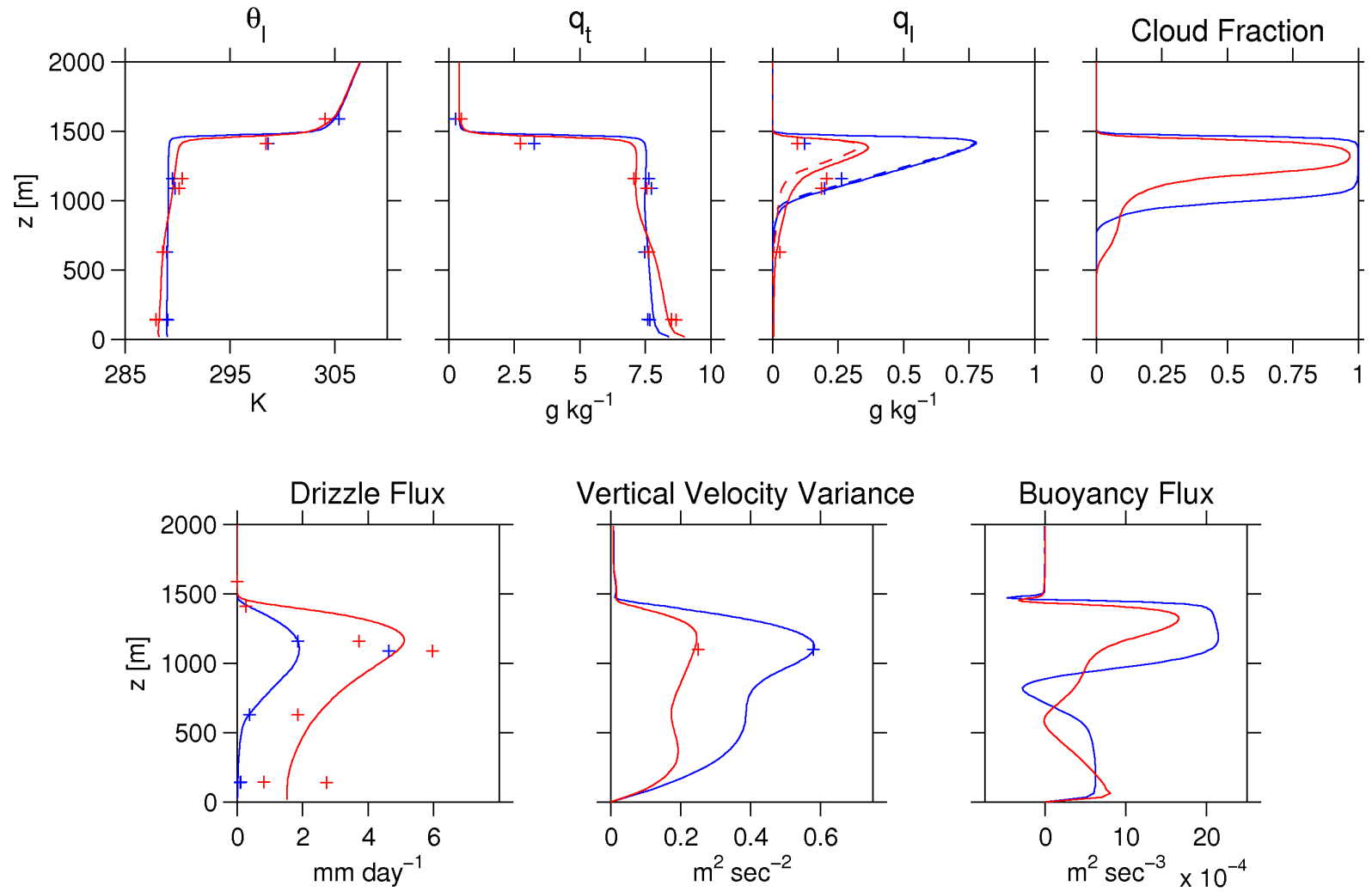

Fig. 8. Region and time averaged profiles for the OVC (blue) and POC (red) regions during the 02:00-04:00 LST comparison period. Flight-leg means from RF06 subset by region are overplotted for reference.

QuickBeam Simulated Cloud Radar

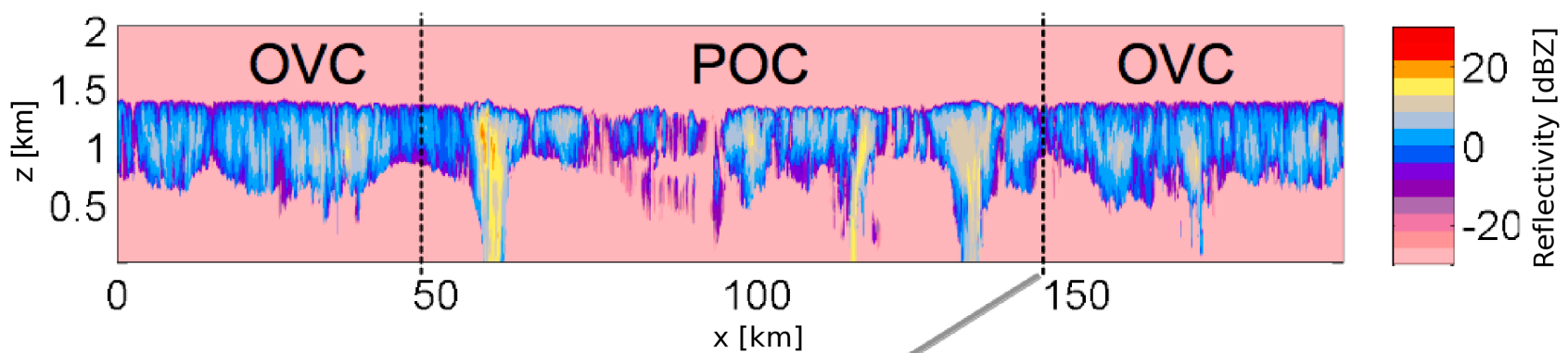

WCR Obs from RF06 SC1

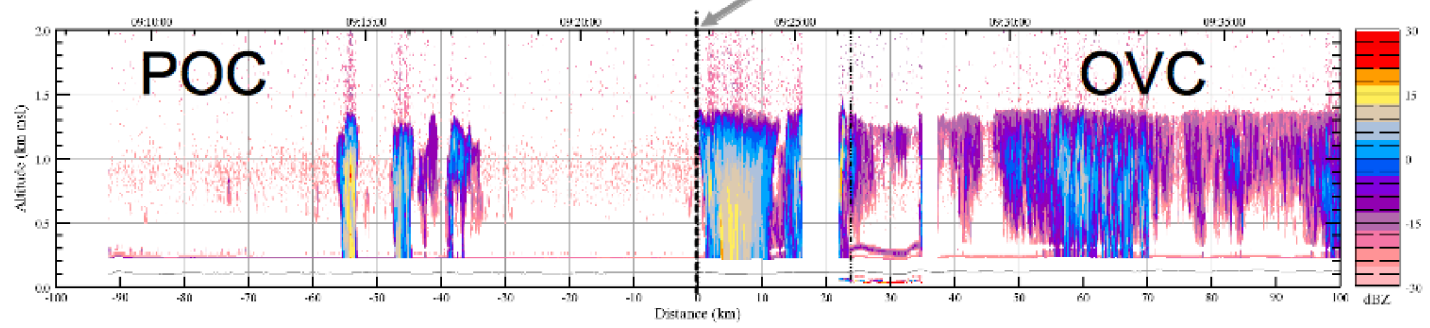

Fig. 9. Comparison of QUICKBEAM simulated cloud radar field to RF06 Wyoming Cloud Radar observations. Plots are on identical spatial and color scales. 
and surrounding overcast, it is difficult to tell to what extent, if any, the simulated diurnal transition matches the behavior of the real system.

Figure 8 depicts temporally and spatially averaged profiles of several variables for the 02:00-04:00 LST interval across the OVC and POC regions. Observations from RF06 are overplotted for reference. The observational values are obtained by separating flight legs into OVC and POC segments and calculating means for each segment.

The $\theta_{l}$ and $q_{t}$ profiles in Fig. $8 \mathrm{a}$ and $\mathrm{b}$ are well-mixed in the OVC region, but decoupled in the $\mathrm{POC}$, which has a cooler and moister surface layer. The simulated POC region is about $0.9 \mathrm{~K}$ warmer than the OVC region in the upper MBL, and $0.8 \mathrm{~K}$ cooler near the surface, in good agreement with the observations. The simulated $q_{\mathrm{t}}$ is $0.4 \mathrm{~g} \mathrm{~kg}^{-1}$ drier in the upper part of the MBL and $0.6 \mathrm{~g} \mathrm{~kg}^{-1}$ moister near the surface in the $\mathrm{POC}$ region than in the OVC region, again comparable to observations.

Figure $8 \mathrm{c}$ presents the average $q_{1}$ profiles, where the dashed line represents non-precipitating cloud water $q_{\mathrm{c}}$. No observations are available at the level of the $q_{1}$ maxima, but agreement near the inversion and cloud base is reasonable, with higher $q_{1}$ present in the OVC than the POC. In the POC, but not in the OVC region, there is a clear separation between the profiles of non-precipitating liquid and total liquid water, indicating that a significant fraction of the liquid water content is in drizzle-sized droplets (larger than 20 micron radius), especially lower within the cloud layer. Quantitative comparison of the model results with the observations for the precipitating/non-precipitating $q_{1}$ fraction is difficult, as this value is quite sensitive to the droplet size selected for the partition, which is not identical between the microphysics module of the model and the observations; nevertheless, this feature is certainly qualitatively correct.

Figure $8 \mathrm{~d}$ shows average cloud fraction profiles, defining a "cloudy" grid cell as one with $q_{\mathrm{c}}$ of at least $0.01 \mathrm{~g} \mathrm{~kg}^{-1}$. The resulting OVC profile shows thick cloud with relatively sharp definition of cloud top and cloud base, while the POC profile has a thinner sheet of cloud with lower peak cloud fraction and more variability in the cloud top and cloud base. The presence of significant cloudiness at lower levels in the POC is indicative of cumuliform cell walls.

Drizzle flux profiles in Fig. 8e reveal enhanced precipitation in the POC with a substantial amount reaching the surface and substantial cloud base drizzle in both the POC and OVC. Quantitative agreement in the rain rate profile in the mean is generally good at the cloud base and surface, where data is available.

The differences in boundary layer turbulence between regions is well captured by the vertical velocity variance and buoyancy flux profiles in Fig. $8 \mathrm{f}$ and g. The OVC $\overline{w^{\prime 2}}$ profile (the overline indicates a horizontal average over the region of interest) appears relatively well coupled, with a maxima in the upper cloud layer and a reduction below cloud due to cloud-base evaporation of drizzle, also evident in the buoyancy flux profile. The POC $\overline{w^{\prime 2}}$ profile has a weak minimum in variance between the surface layer and the cloud layer consistent with a decoupled vertical structure. Average variance in the POC is significantly weaker, with a peak value of $0.25 \mathrm{~m}^{2} \mathrm{~s}^{-2}$, compared to the OVC, with a peak value of $0.58 \mathrm{~m}^{2} \mathrm{~s}^{-2}$. This is in good agreement with the observed cloud-leg mean values of $0.60 \mathrm{~m}^{2} \mathrm{~s}^{-2}$ in the OVC and $0.32 \mathrm{~m}^{2} \mathrm{~s}^{-2}$ in the POC Wood et al. (2011b).

The NCAR C-130 flew equipped with the $94 \mathrm{GHz}$ vertically-pointing Wyoming Cloud Radar (WCR) to probe clouds and precipitation. The radar echo is particularly sensitive to large drizzle drops, and provides a useful test of the model's simulated precipitation characteristics. Figure 9 shows a representative model cross-section using the QUICKBEAM simulated millimeter wave radar reflectivity field and the WCR output from RF06 SC1, plotted on the same spatial scale with matched color maps. The simulated radar returns in the model are generally stronger, though peak intensity is comparable. While only $25 \%$ of columns in the OVC region of the observations had returns above $0 \mathrm{dBZ}$, nearly $90 \%$ of OVC columns in the NCFIXED run exceed this threshold between 02:00-04:00 LST. In the POC region, $7 \%$ of observed columns have reflectivities in excess of $10 \mathrm{dBZ}$, while $30 \%$ of columns in the model POC are larger during the comparison period. In spite of the radar bias, Fig. 8e shows very good agreement for model precipitation profiles with observations. This suggests the simulated drizzle droplet size spectra has too large a tail at large drop sizes. Ongoing work to compare model droplet size spectra with observations should shed more light on this bias.

\subsection{Mesoscale structure}

Figure 10 shows a series of $y$-averaged snapshots of precipitation with the $q_{\mathrm{c}}=0.01 \mathrm{~g} \mathrm{~kg}^{-1}$ contour overlaid to mark cloud top and cloud base. This illustrates the difference in the character of precipitation between the POC (where it reaches the surface) and OVC (where it largely evaporates before reaching the surface). The cloud base is relatively uniform in the OVC region, while cumuliform updrafts are readily evident within the POC. Strong precipitation cells appear at the edges of the POC and shift inwards as the simulation progresses, while pockets of weak surface precipitation appear closer to the overcast region. By 06:00 LST, while the most intense surface precipitation is still found within the POC region, the overcast region has also developed a significant amount of surface precipitation, helping to decouple the boundary layer.

The time evolution of the $y$-averaged liquid water path shown in Fig. 6 demonstrates some interesting structural features. After the initial spin-up, a sharp difference in LWP is established. The propagation of the eddies that set up on the boundary into the domain is evident as the line of enhanced LWP shifting inwards from the initial boundary. Similarly, a region of enhanced LWP moves outwards from the initial 


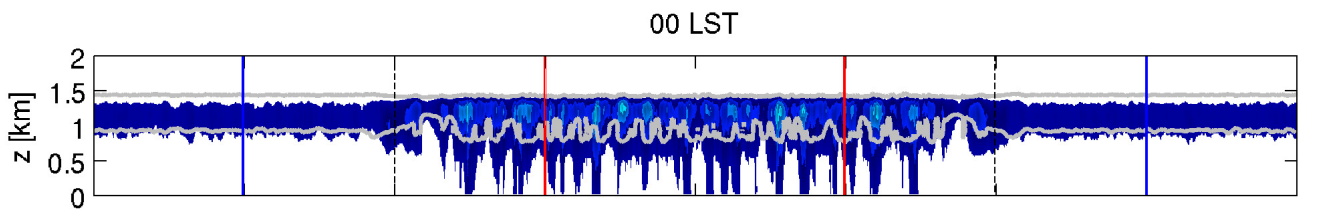

02 LST
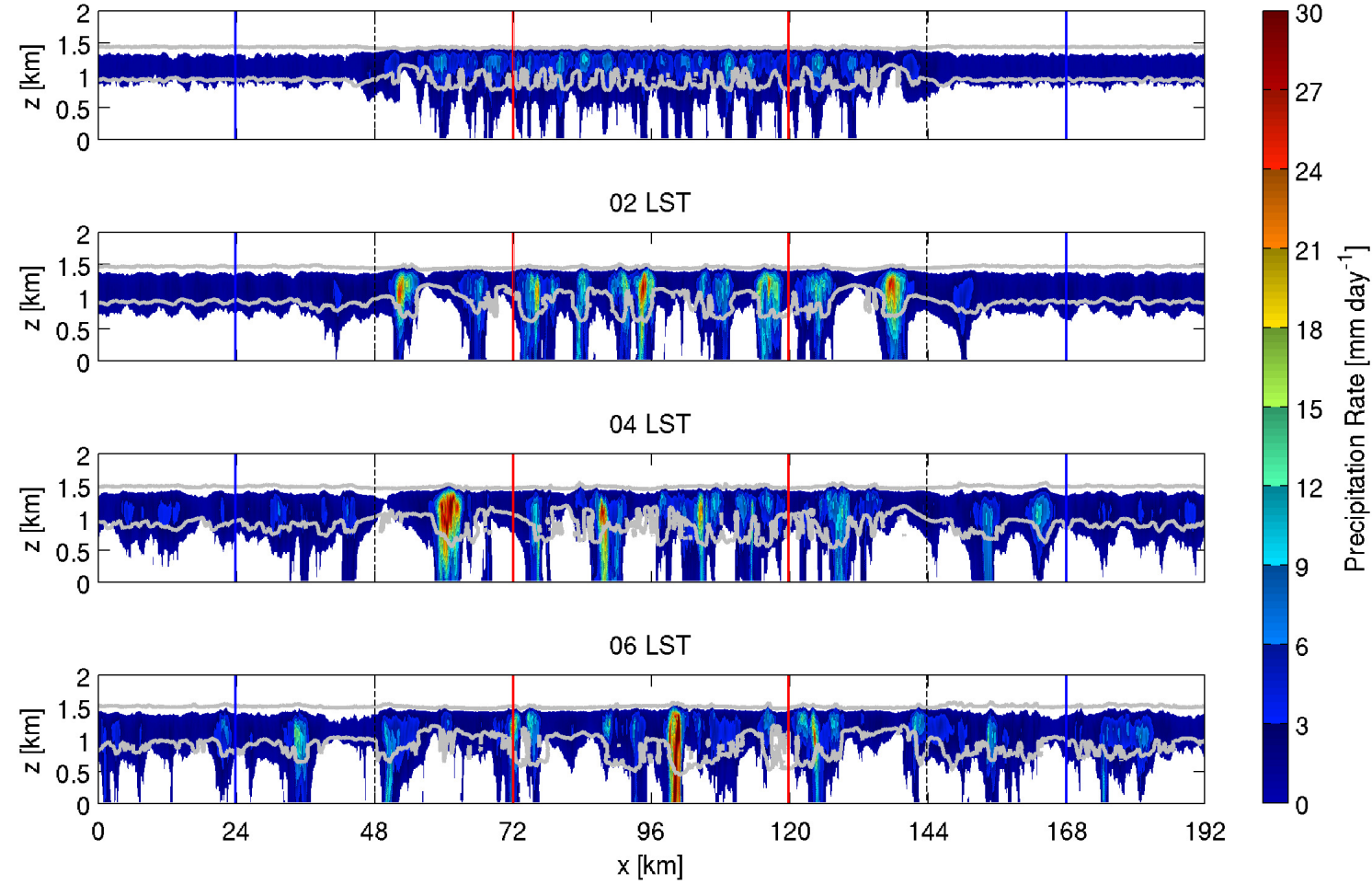

Fig. 10. $y$-averaged $x-z$ snapshots of the precipitation with the $q_{\mathrm{c}}=0.01 \mathrm{~g} \mathrm{~kg}^{-1}$ contour overlaid to show cloud structure.
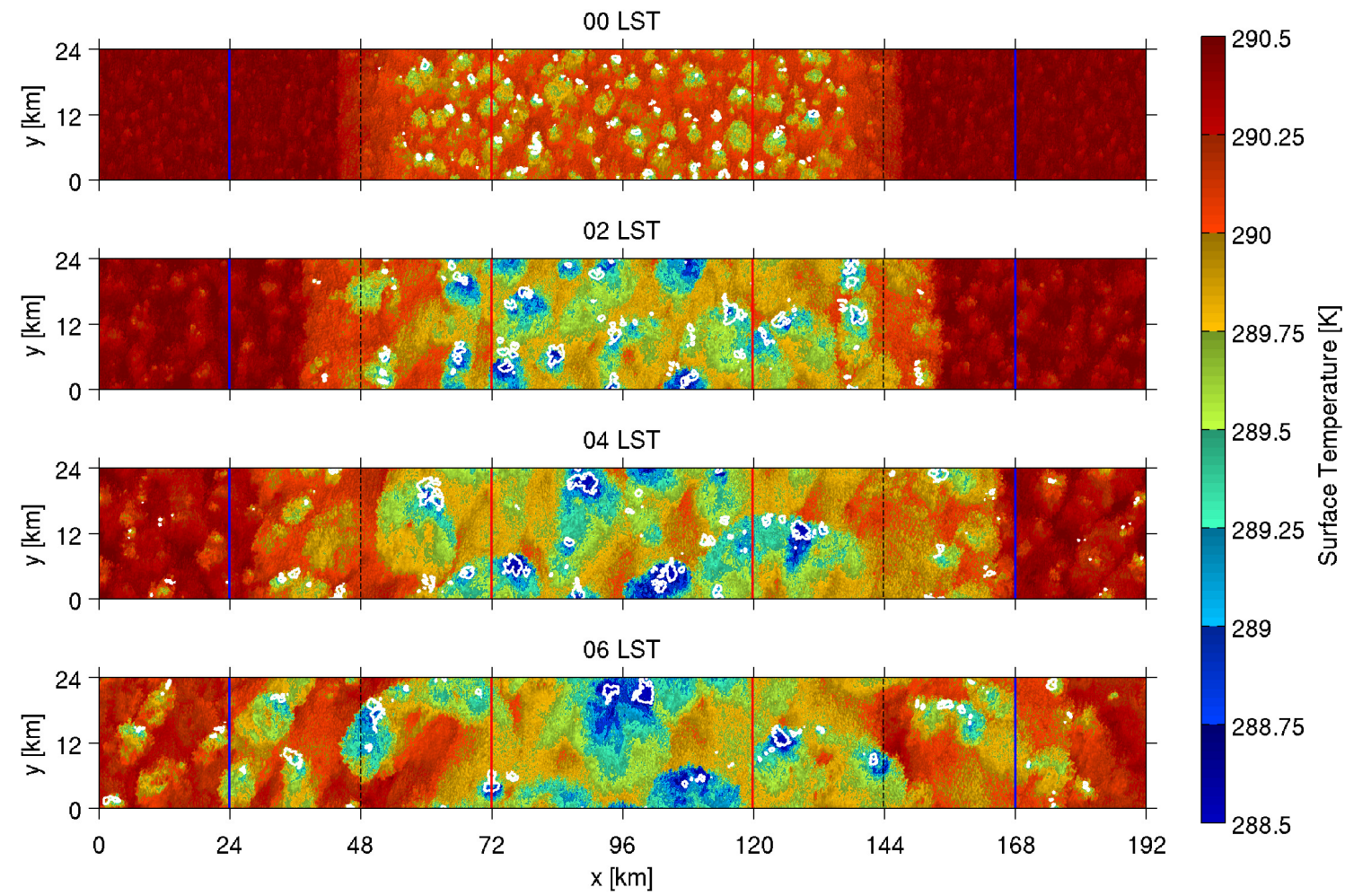

Fig. 11. $x-y$ snapshots of the $15 \mathrm{~m}$ air temperature with a $10 \mathrm{~mm} \mathrm{day}^{-1}$ precipitation contour to show intense drizzle reaching the surface. 


\section{Two-hour mean streamfunction $\Psi^{\prime}$}
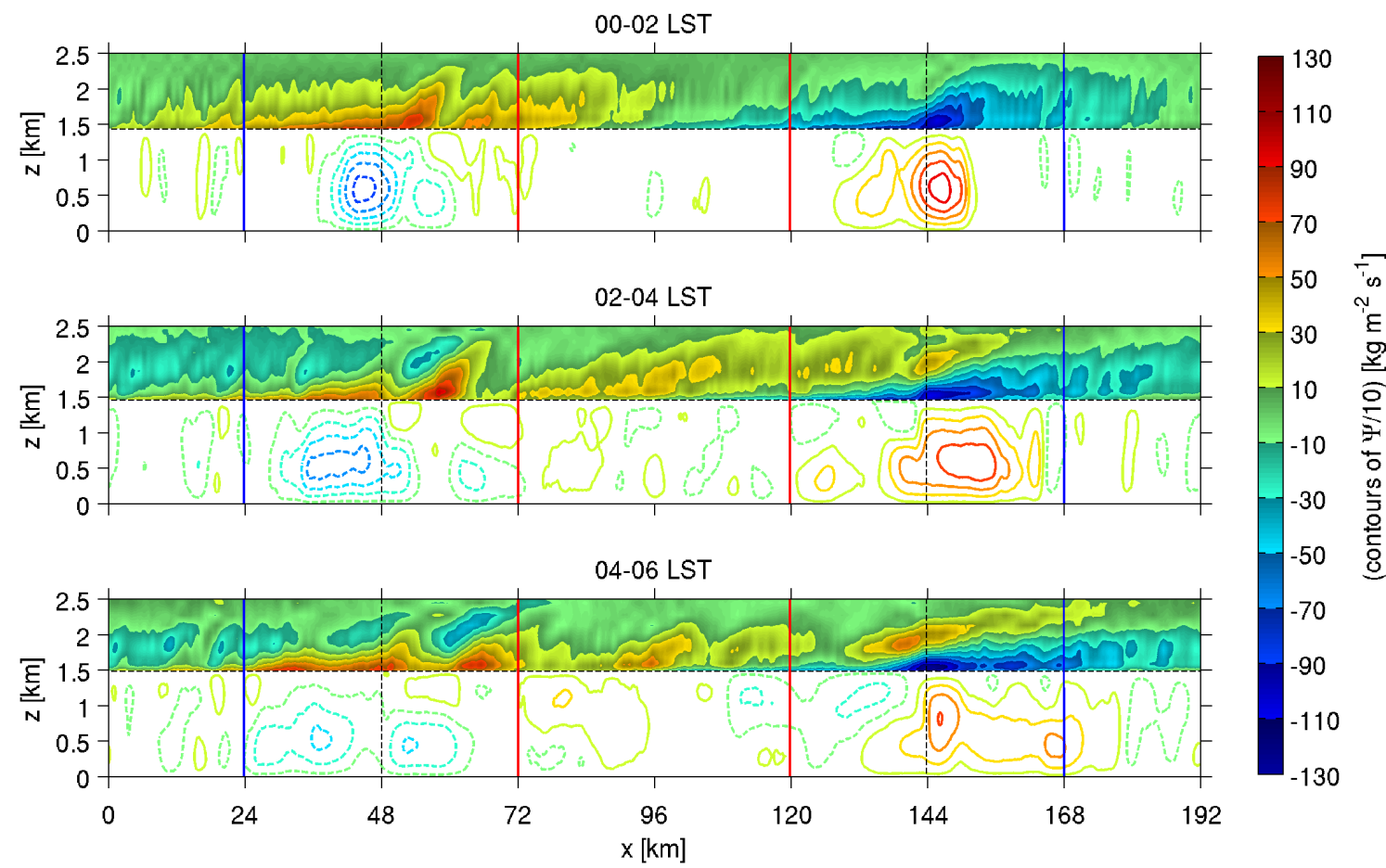

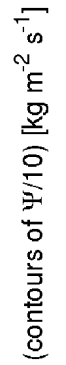
$-70$ $-90$ $-110$ $-130$

Fig. 12. $y$ and two-hour time-averaged $x-z$ cross-sections of the perturbation streamfunction $\Psi^{\prime}$. The filled circulations are above the domain mean inversion. Contours are on the same color scale as the filled region, but are an order of magnitude larger in value.

boundary associated with convergence at the leading edge of the mesoscale cold pool spreading outwards from the POC. Cells in the POC are also more oscillatory and short lived, with new maxima appearing between prior maxima as time advances, in accord with Feingold (2010). The locations of LWP maxima in the OVC region vary much less rapidly.

As discussed in Wang et al. (2010), cold pool spreading plays an important role in the dynamics of POCs. Figure 11 shows snapshots of $15 \mathrm{~m}$ temperature with $10 \mathrm{~mm} \mathrm{day}^{-1}$ drizzle contours overlaid in white. Between 00:00 and 04:00 LST, the edge of the surface temperature gradient shifts outwards roughly $20 \mathrm{~km}$ from the initial POC boundary. The spreading cold pool maintains itself by enhancing updrafts where it undercuts the OVC region, leading to enhanced LWP and stronger drizzle rates. The results from Figs. 6, 11 , and 8 make it possible to compare the rate of cold pool spreading with the theoretical velocity $V$ for a density current, $V \propto \sqrt{g \theta_{v}^{\prime} H / \theta_{v}}$, where $H$ is the density current depth, $g$ is the gravitational constant, $\theta_{v}^{\prime}$ is the perturbation virtual potential temperature for the current, and $\theta_{v}$ is the background virtual potential temperature. The cold pool spreads away from the POC roughly $24 \mathrm{~km}$ in $6 \mathrm{~h}$, or roughly $1.1 \mathrm{~m} \mathrm{~s}^{-1}$. Using $H=500 \mathrm{~m}, \theta_{v}^{\prime}=0.3 \mathrm{~K}$ (an average between double this value at the surface and zero at the height $H$ ), and $\theta_{v}=290 \mathrm{~K}, V \approx 2.2 \mathrm{~m} \mathrm{~s}^{-1}$. While this is larger than the estimated spreading rate, the cold pool is propagating against a $1 \mathrm{~m} \mathrm{~s}^{-1}$ background flow converging into the POC in the upper part of the boundary layer.

Figure 12 depicts a series of cross sections of the temporally and $y$-averaged streamfunction using two hours of model output sampled every $10 \mathrm{~min}$ for each section. The shaded region shows circulations above the inversion, while contours describe circulations within the boundary layer. Note that contours are on the same color scale, but an order of magnitude stronger than the shaded circulations. Cooler colors and dashed contours are clockwise circulations, while warmer colors and solid colors are counter-clockwise. The 00:00-02:00 LST section shows particularly well-defined eddies with significant flow in the upper MBL from the OVC into the POC, and low level outflow from the POC to the OVC. These eddies start at the POC boundary, but spread away from it with time, an effect visible in Fig. 6 as LWP maxima at the initial POC edge that subsequently propagate inwards. The outer (upward) branch of the eddy circulation roughly overlies the spreading cold pool edge, and the downward branch propagates into the POC. They have only a loose correlation with precipitation, and should probably not be interpreted as a model analogue to the pronounced boundary cells observed in RF06 by Wood et al. (2011b). Similar behavior was observed in the simulations of Wang and Feingold (2009b). This eddy propagation may merely be a spin-up artifact, as field or satellite observations have not shown this 

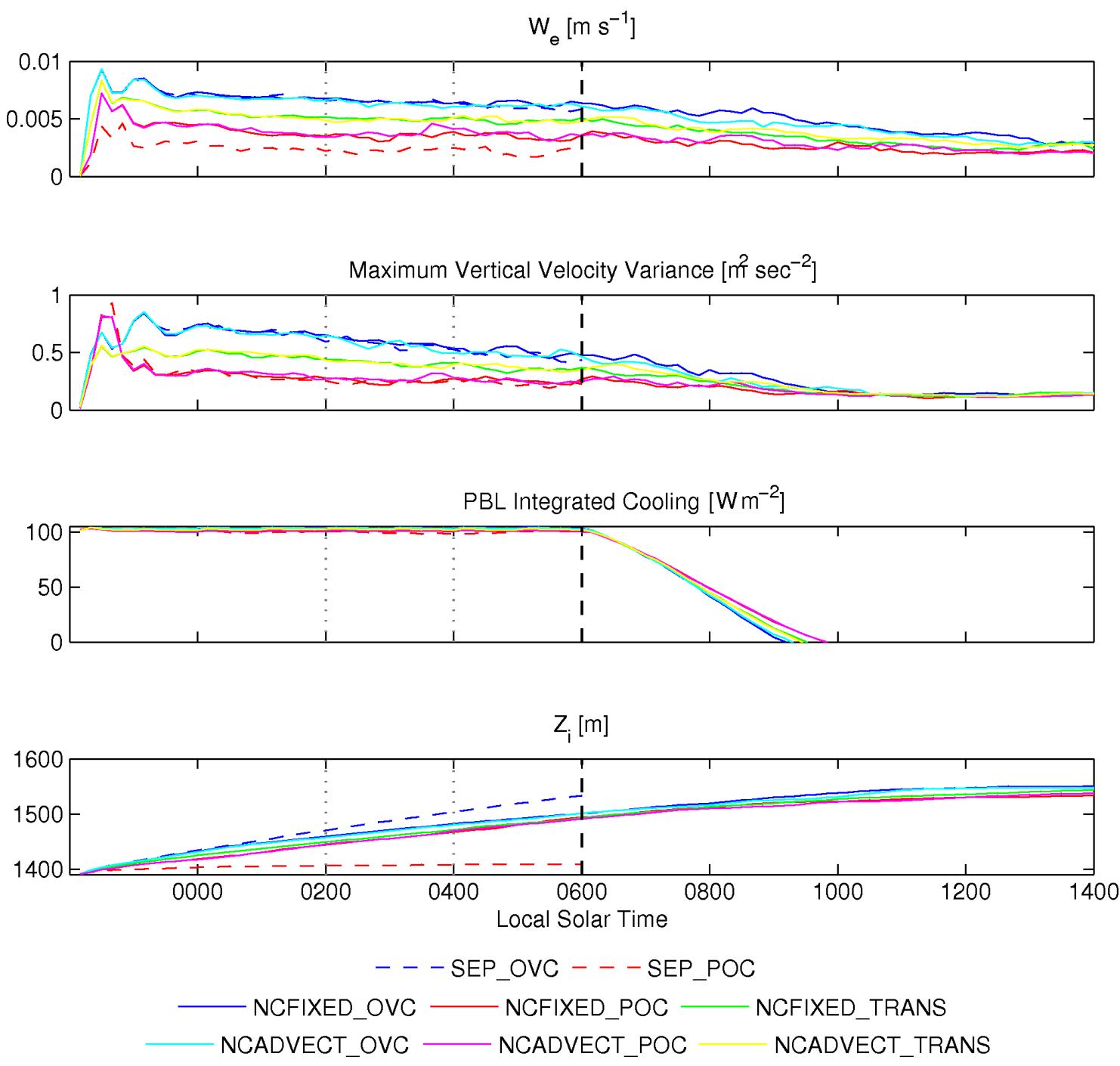

Fig. 13. Region averaged time series of entrainment-related quantities for all model runs. Sunrise is at 06:00 LST (vertical dashed line).

behavior in an actual POC. Weaker circulations are evident immediately above the inversion, in the reverse sense as the MBL eddies. While shear across the inversion stretches the above inversion circulation out somewhat, the overall structure persists through sunrise.

\subsection{Entrainment}

Our simulations reveal some interesting aspects of entrainment in the OVC/POC system. We diagnose entrainment with two methods: flux-jump (e.g. Faloona et al., 2005) of an initial tracer field initialized with concentration of unity above the initial inversion and zero in the MBL, and the mean inversion method (Bretherton et al., 1998), where the inversion height in each column is defined as the linearlyinterpolated level of the $50 \%$ relative humidity surface. These methods agree with each other to within ten percent regionally and within one percent in the domain average. The flux-jump method is retrievable from a snapshot of the tracer and velocity fields, while the mean inversion method requires differencing of the inversion height across several timesteps; as such, the flux-jump method is used in preference to the mean inversion approach.

Figure 13a shows that during the period 02:00-04:00 LST, there is nearly twice as much entrainment $\left(6.5 \mathrm{~mm} \mathrm{~s}^{-1}\right.$; the solid blue curve) in the OVC region as in the POC region $\left(3.8 \mathrm{~mm} \mathrm{~s}^{-1}\right.$; the solid red curve). So far, we do not have an observational analysis that separately estimates entrainment rates inside and outside the POC, but Wood et al. (2011b) estimated a POC/OVC average entrainment rate of $4.5 \pm 1 \mathrm{~mm} \mathrm{~s}^{-1}$ from the Lagrangian rise rate of the inversion from a previous flight the previous evening and an estimated subsidence rate, with further constraints provided by energy and moisture budgets. The observational estimate has numerous uncertainties, but is consistent with the simulated 


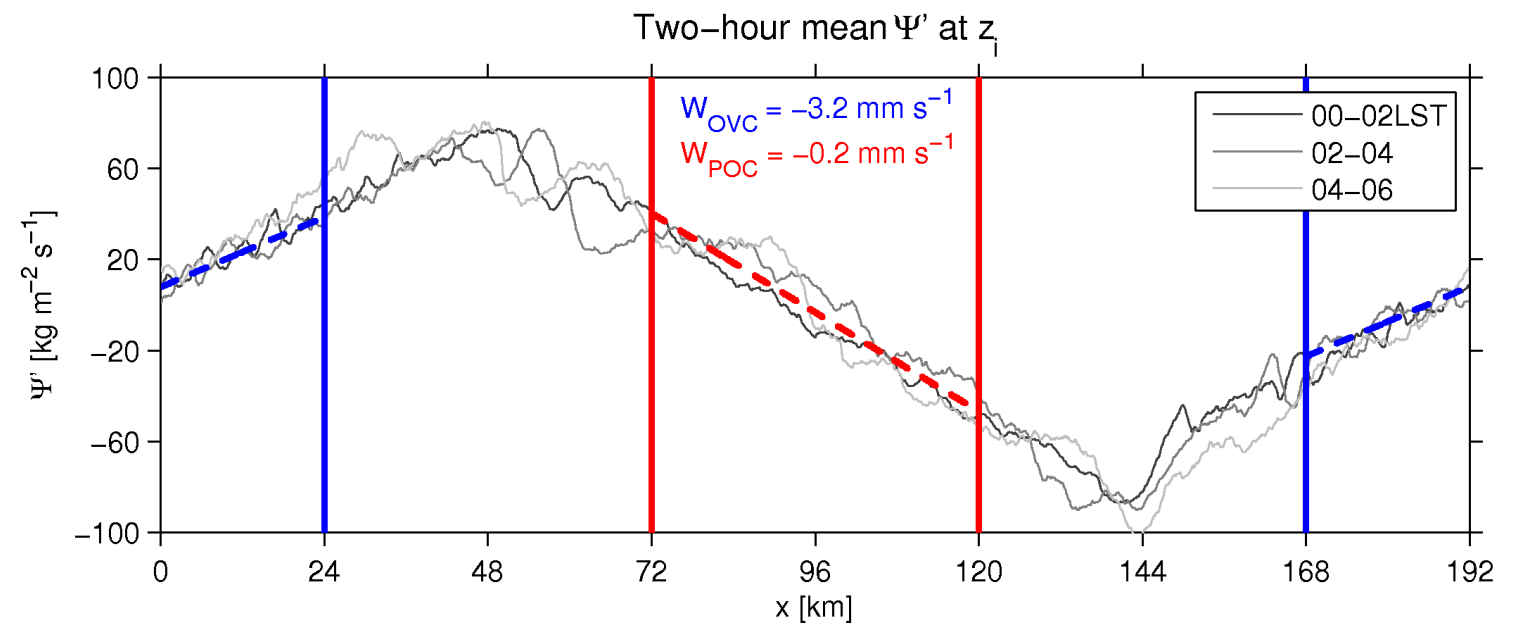

Fig. 14. Traces of magnitude for two-hour means of the $y$-averaged perturbation streamfunction $\Psi^{\prime}$ at the level of the domain-mean inversion. The $y$-averaged stream function at the nearest grid level to the domain mean $Z_{i}$ is calculated from each 3-D model output (i.e. every ten minutes), and the plots average together two hours of these traces.

domain average entrainment rate of $5.5 \mathrm{~mm} \mathrm{~s}^{-1}$ during the comparison period. This entrainment difference is qualitatively consistent with the stronger turbulence in the overcast region shown in Fig. 8f and the column-maximum vertical velocity variance time series in Fig. $13 \mathrm{~b}$.

The boundary layer integrated radiative cooling time series in Fig. 13c shows that the radiative forcing is similar in the two regions, with cooling rates of $-103 \mathrm{~W} \mathrm{~m}^{-2}$ in the OVC and $-101 \mathrm{~W} \mathrm{~m}^{-2}$ in the POC. This suggests that differences in radiative forcing between regions of the domain is not a large contributor to the simulated differences in entrainment rate, and that instead structural differences in the boundary layer structure create the bulk of the difference in entrainment.

Figure $13 \mathrm{~d}$ shows time series for the inversion height, calculated by interpolating the height of the $50 \%$ relative humidity level in each column within a region, then averaging the columns in each region. Interestingly, the inversion rises more or less evenly across the whole domain despite the regional difference in entrainment, though the inversion height in the POC is typically $15 \mathrm{~m}$ lower. The secondary circulations discussed in Sect. 4.3 must thus balance POC-scale variability in entrainment, so as to reduce subsidence over the POC and enhance it over the OVC region. This can be seen directly from Fig. 12, where one sees red shades (positive streamfunction) at the inversion at the left edge of the POC and blue shades (negative streamfunction) at the inversion at the right edge of the POC, with the strongest streamfunction anomalies localized within $200 \mathrm{~m}$ of the inversion height.

A more quantitative analysis is shown in Fig. 14, which plots the value of the stream function at the domain meaninversion level as a function of $x$ coordinate for the same two-hour averaging periods used for Fig. 12. Oscillations in the individual traces within $\pm 12 \mathrm{~km}$ of the original boundary at $x=48 \mathrm{~km}$ and $x=144 \mathrm{~km}$ reflect the mesoscale boundary eddies. Since $-\partial \Psi^{\prime} / \partial x=w^{\prime}$, the perturbation vertical velocity is generally positive in the POC and negative in the OVC, as shown by the red and blue-dashed fit lines, respectively. When the large scale subsidence $w_{\text {ls }}$ is added, these fit lines yield 6-h mean values of $w_{\mathrm{OVC}}=-3.2 \mathrm{~mm} \mathrm{~s}^{-1}$ and $w_{\mathrm{POC}}=-0.2 \mathrm{~mm} \mathrm{~s}^{-1}$. That is, essentially all of the mean subsidence is diverted from above the POC into the surrounding overcast region! Figure 18 from Bretherton et al. (2010) shows a cartoon depiction of such a circulation in qualitative agreement with the modeled circulation. From Fig. 12, the horizontal flow diversion mainly occurs in a 300-500 m layer above the inversion, and the divergent horizontal velocity at the edges of the simulated POC due to this flow diversion is a few tenths of a meter per second.

In an effort to understand the effects of the POC region on the boundary-layer development and entrainment rate in the neighboring OVC region and vice versa, sensitivity studies of boundary-layer development in isolated, homogeneous $24 \mathrm{~km} \times 24 \mathrm{~km}$ domains were conducted with the same initialization and forcings as our NCFIXED control run, but using POC and OVC $N_{\mathrm{c}}$ values across the whole domain. Surprisingly, while the OVC-only simulation entrained at a rate nearly identical to that diagnosed in the OVC region of the control simulations, the POC-only simulation entrained $30 \%$ less in isolation, as seen in Fig. 13a, even though its turbulent velocity variance in the cloud layer is almost identical to the combined run. We speculate this may reflect a subtly different inversion structure over the POC in the combined run compared to the POC-only simulation, but this requires further study.

As a further sensitivity study, homogeneous runs in the small domain were conducted at lower $N_{\mathrm{c}}$ values of 5 and $1 \mathrm{~cm}^{-3}$, as well as a run in which $N_{\mathrm{c}}$ is set to $10 \mathrm{~cm}^{-3}$ and 
large scale subsidence is set to zero. The trial in which subsidence is set to zero develops a cloud fraction of $97 \%$, LWP of $118 \mathrm{~g} \mathrm{~m}^{-2}$, and entrainment rate of $2.5 \mathrm{~mm} \mathrm{~s}^{-1}$, essentially identical with the POC-only simulation in which subsidence is included. While subsidence in the POC-only run has a statistically indistinguishable effect on LWP and entrainment, further reductions of $N_{\mathrm{c}}$ have marked impacts, with cloud fraction reducing to $63 \%$ and $37 \%$ after eight hours in the runs with $N_{\mathrm{c}}$ set to 5 and $1 \mathrm{~cm}^{-3}$, respectively. At the same time, liquid water path reductions are modest, with hour eight LWPs of 77 and $48 \mathrm{~g} \mathrm{~m}^{-2}$. Interestingly, entrainment drops significantly, falling to 1.2 and $0.3 \mathrm{~mm} \mathrm{~s}^{-1}$, suggesting that excess thin stratocumulus within the POC is responsible for the majority of entrainment there.

Differential entrainment has implications for aerosol feedbacks not yet represented in the model. For the RF06 case, Kazil et al. (2011) suggest that entrainment from the free troposphere and surface production are both important sources of CCN. Weaker entrainment into the POC suggests that the OVC region will preferentially mix in additional $\mathrm{CCN}$ from the free troposphere, helping to support a higher $N_{\mathrm{c}}$ and lower drizzle rates in the surrounding OVC region. This is a possible positive feedback (in addition to the direct feedback of enhanced precipitation scavenging on aerosol for lower $N_{\mathrm{c}}$ ) that helps maintain the OVC/POC system in place.

\section{Conclusions}

We have shown that when driven by specified gradients in cloud droplet concentration, a realistically initialized and forced LES is capable of reproducing the dynamics of an archetypical observed POC and its interaction with the surrounding overcast region, agreeing well in most properties other than cloud fraction. If droplet concentration is instead allowed to advect, the 16-h simulation is little changed because the POC is too big for the initial droplet concentration gradients to turbulently diffuse away in this time.

Although the simulation is initialized with a horizontally uniform cloud layer, within an hour, the gradients in droplet concentration produce twofold differences in mean liquid water path between the overcast and POC region, and precipitation in the POC region induces boundary layer decoupling. In both regions, mesoscale circulations develop and broaden throughout the simulation, but the process is much accelerated in the POC, where pronounced precipitation-driven cold pools quickly organize the cells. As observed, the nearsurface air is cooler under the POC. The cool air slowly spreads into and undercuts the overcast region during the simulation, inducing decoupling and the formation of new precipitating cells at its leading edge.

Entrainment into the POC is only half as large as in the surrounding overcast region because cloud-layer turbulence is weaker and more spatially intermittent. Because the strong inversion does not support large horizontal gradients in inver- sion height, subsiding air is channelled away from the POC into the overcast region, so the inversion deepens at the same rate in both regions despite the differential entrainment.

A major limitation of the current study is that cloud droplet number concentration is specified rather than being realistically predicted from a sophisticated model of cloud-aerosolchemistry interaction as in Kazil et al. (2011). Instead, we have focused in this paper on aspects of the POC dynamics that do not heavily depend on this interaction. However, to simulate the interaction of POCs and their surroundings over longer time periods and with more realism, we plan to add interactive aerosols into our LES and re-examine the role of entrainment feedbacks on POC development and maintenance.

Acknowledgements. Thanks to Peter Blossey at UW for creating the SAM interface for the Morrison microphysics scheme and answering a plethora of questions regarding model formulation and implementation details. We are also extremely grateful to Marat Khairoutdinov of Stony Brook University for maintaining and providing SAM for use in this study. The authors gratefully acknowledge support from NSF grant ATM-0745702.

Edited by: H. Coe

\section{References}

Ackerman, A. S., Kirkpatrick, M., Stevens, D., and Toon, O.: The impact of humidity above stratiform clouds on indirect aerosol climate forcing, Nature, 432, 1014-1017, 2004.

Ackerman, A. S., vanZanten, M. C., Stevens, B., Savic-Jovcic, V., Bretherton, C. S., Chlond, A., Golaz, J. C., Jiang, H., Khairoutdinov, M., Krueger, S. K., Lewellen, D. C., Lock, A., Moeng, C. H., Nakamura, K., Petters, M. D., Snider, J. R., Weinbrecht, S., and Zulauf, M.: Large-eddy simulations of a drizzling, stratocumulus-topped marine boundary layer, Mon. Weather Rev., 137, 1083-1110, 2009.

Bretherton, C. S., Macvean, M. K., Bechtold, P., Chlond, A., Cotton, W. R., Cuxart, J., Cuijpers, H., Khairoutdinov, M., Kosovic, B., Lewellen, D., Moeng, C.-H., Siebesma, P., Stevens, B., Stevens, D. E., Sykes, I., and Wyant, M. C.: An intercomparison of radiatively driven entrainment and turbulence in a smoke cloud, as simulated by different numerical models, Q. J. Roy. Meteorol. Soc., 125, 391-423, 1998.

Bretherton, C. S., Uttal, T., Fairall, C. W. , Yuter, S., Weller, R., Baumgardner, D., Comstock, K., and Wood, R.: The EPIC 2001 stratocumulus study, B. Am. Meteorol. Soc., 85, 967-977, 2004.

Bretherton, C. S., Blossey, P. N., and Uchida, J.: Cloud droplet sedimentation, entrainment efficiency, and subtropical stratocumulus albedo, Geophys. Res. Lett., 34, L03813, doi:10.1029/2006GL027648, 2007.

Bretherton, C. S., Blossey, P. N., and Uchida, J.: Slow manifolds and multiple equilibria in stratocumulus-capped boundary layers, J. Adv. Model. Earth Syst., 2, 14, doi:10.3894/JAMES.2010.2.14 , 2010.

Caldwell, P. and Bretherton, C. S.: Large eddy simulation of the diurnal cycle in Southeast Pacific stratocumulus. J. Atmos. Sci., 66, 432-449, 2009. 
Collins, W. D., Bitz, C. M., Blackmon, M. L., Bonan, G. B., Bretherton, C. S., Carton, J. A., Chang, P., Doney, S. C., Hack, J. J., Henderson, T. B., Kiehl, J. T., Large, W. G., McKenna, D. S., Santer, B. D., and Smith, R. D.: The Community Climate System Model version 3 (CCSM3), J. Climate, 19, 2122-2143, 2006.

Comstock, K., Bretherton, C. S., and Yuter, S.: Mesoscale variability and drizzle in Southeast Pacific stratocumulus, J. Atmos. Sci., 62, 3792-3807, 2005.

Deardorff, J.: Stratocumulus-capped mixed layers derived from a three-dimensional model, Bound.-Lay. Meteor., 18, 495-527, 1980.

Faloona, I., Lenschow, D., Campos, T., Stevens, B., vanZanten, M., Blomquist, B., Thornton, D., Bandy, A., and Gerber, H.: Observations of entrainment in Eastern Pacific marine stratocumulus using three conserved scalars, J. Atmos. Sci, 62, 3268-3285, 2005.

Feingold, G., Koren, I., Wang, H., Xue, H., and Brewer, W. A.: Precipitation-generated oscillations in open cellular cloud fields, Nature, 466, 849-852, 2010.

Garreaud, R. D. and Muñoz, R.: The diurnal cycle in circulation and cloudiness over the subtropical Southeast Pacific: A modeling study, J. Climate, 17, 1699-1710, 2004.

Haynes, J., Luo, Z., Stephens, G. L., Marchand, R. T., and BodasSalcedo, A.: A multipurpose radar simulation package: QuickBeam, B. Am. Meteorol. Soc., 88, 723-1727, 2007.

Kollias, P., Fairall, C. W., Zuidema, P., Tomlinson, J., and Wick, G. A.: Observations of marine stratocumulus in SE Pacific during the PACS 2003 cruise, Geophys. Res. Lett., 31, L22110,doi:10.1029/2004GL020751, 2004.

Morrison, H., Thompson, G., and Tatarskii, V.: Impact of cloud microphysics on the development of trailing stratiform precipitation in a simulated squall line: Comparison of one- and two-moment schemes, Mon. Weather Rev., 137, 991-1007, 2009.

Kazil, J., Wang, H., Feingold, G., Clarke, A. D., Snider, J. R., and Bandy, A. R.: Modeling chemical and aerosol processes in the transition from closed to open cells during VOCALS-REx, Atmos. Chem. Phys., 11, 7491-7514, doi:10.5194/acp-11-74912011, 2011.

Khairoutdinov, M. F. and Randall, D. A.: Cloud resolving modeling of the ARM summer 1997 IOP: Model formulation, results, uncertainties, and sensitivities, J. Atmos. Sci., 60, 607-625, 2003.

Savic-Jovcic, V. and Stevens, B.: The structure and mesoscale organization of precipitating stratocumulus, J. Atmos. Sci., 65, 15871605, 2008.

Sharon, T. M., Albrecht, B. A., Jonsson, H., Minnis, P., Khaiyer, M. M., VanReken, T. M., Seinfeld, J., and Flagan, R.: Aerosol and cloud microphysical characteristics of rifts and gradients in maritime stratocumulus clouds, J. Atmos. Sci., 63, 983-997, 2005.
Stevens, B., Moeng, C. H., and Sullivan, P.: Large-eddy simulations of radiatively driven convection: Sensitivities to the representation of small scales, J. Atmos. Sci., 56, 3963-3984, 1999.

Stevens, B., Vali, G., Comstock, K., Wood, R., vanZanten, M. C., Austin, P. H., Bretherton, C. S., and Lenschow, D. H.: Pockets of open cells and drizzle in marine stratocumulus, B. Am. Meteorol. Soc., 86, 51-57, 2005.

vanZanten, M. C. and Stevens, B.: Observations of drizzle in nocturnal marine stratocumulus, J. Atmos. Sci., 62, 88-106, 2005.

Wang, H. and Feingold, G.: Modeling mesoscale cellular structures and drizzle in marine stratocumulus, Part I: Impact of drizzle on the formation and evolution of open cells, J. Atmos. Sci., 66, 3237-3256, 2009a.

Wang, H. and Feingold, G.: Modeling mesoscale cellular structures and drizzle in marine stratocumulus, Part II: The microphysics and dynamics of the boundary region between open and closed cells, J. Atmos. Sci., 66, 3257-3275, 2009b.

Wang, H., Feingold, G., Wood, R., and Kazil, J.: Modelling microphysical and meteorological controls on precipitation and cloud cellular structures in Southeast Pacific stratocumulus, Atmos. Chem. Phys., 10, 6347-6362, doi:10.5194/acp-10-6347-2010, 2010.

Wood, R., Köhler, M., Bennartz, R., and O'Dell, C.: The diurnal cycle of surface divergence over the global oceans, Q. J. Roy. Meteorol. Soc., 135, 1484-1493, 2009.

Wood, R., Mechoso, C. R., Bretherton, C. S., Weller, R. A., Huebert, B., Straneo, F., Albrecht, B. A., Coe, H., Allen, G., Vaughan, G., Daum, P., Fairall, C., Chand, D., Gallardo Klenner, L., Garreaud, R., Grados, C., Covert, D. S., Bates, T. S., Krejci, R., Russell, L. M., de Szoeke, S., Brewer, A., Yuter, S. E., Springston, S. R., Chaigneau, A., Toniazzo, T., Minnis, P., Palikonda, R., Abel, S. J., Brown, W. O. J., Williams, S., Fochesatto, J., Brioude, J., and Bower, K. N.: The VAMOS Ocean-Cloud-Atmosphere-Land Study Regional Experiment (VOCALS-REx): goals, platforms, and field operations, Atmos. Chem. Phys., 11, 627-654, doi:10.5194/acp-11-6272011, 2011a.

Wood, R., Bretherton, C. S., Leon, D., Clarke, A. D., Zuidema, P., Allen, G., and Coe, H.: An aircraft case study of the spatial transition from closed to open mesoscale cellular convection over the Southeast Pacific, Atmos. Chem. Phys., 11, 2341-2370, doi:10.5194/acp-11-2341-2011, 2011b.

Zhang, Y., Stevens, B., and Ghil, M.: On the diurnal cycle and susceptibility to aerosol concentration in a stratocumulus-topped mixed layer, Q. J. Roy. Meteorol. Soc., 131, 1567-1583, 2005. 